\title{
Targeting histone methyltransferase and demethylase in acute myeloid leukemia therapy
}

This article was published in the following Dove Press journal:

OncoTargets and Therapy

\section{Germana Castelli \\ Elvira Pelosi \\ Ugo Testa}

Department of Oncology, Istituto Superiore di Sanità, Rome, Italy

Correspondence: Ugo Testa Department of Oncology, Istituto Superiore di Sanità, 299 Viale Regina Elena, Rome 0016I, Italy $\mathrm{Tel}+390649902422$

Fax +90 0649387087

Email ugo.testa@iss.it

\begin{abstract}
Acute myeloid leukemia (AML) is a clonal disorder of myeloid progenitors characterized by the acquisition of chromosomal abnormalities, somatic mutations, and epigenetic changes that determine a consistent degree of biological and clinical heterogeneity. Advances in genomic technologies have increasingly shown the complexity and heterogeneity of genetic and epigenetic alterations in AML. Among the genetic alterations occurring in AML, frequent are the genetic alterations at the level of various genes involved in the epigenetic control of the DNA methylome and histone methylome. In fact, genes involved in DNA demethylation (such as $D N M T 3 A$, TET2, IDH1, and IDH2) or histone methylation and demethylation (EZH2, MLL, $D O T 1 L)$ are frequently mutated in primary and secondary AML. Furthermore, some histone demethylases, such as LSD1, are frequently overexpressed in AML. These observations have strongly supported a major role of dysregulated epigenetic regulatory processes in leukemia onset and development. This conclusion was further supported by the observation that mutations in genes encoding epigenetic modifiers, such as DMT3A, ASXL1, TET2, IDH1, and IDH2, are usually acquired early and are present in the founding leukemic clone. These observations have contributed to development of the idea that targeting epigenetic abnormalities could represent a potentially promising strategy for the development of innovative treatments of AML. In this review, we analyze those proteins and their inhibitors that have already reached the first stages of clinical trials in AML, namely the histone methyltransferase DOT1L, the demethylase LSD1, and the MLL-interacting protein menin.
\end{abstract}

Keywords: acute myeloid leukemia, epigenetic modifications, methyltransferases, demethylases

\section{Introduction}

\section{Epigenetic modification of DNA}

In the nucleus of eukaryotic cells, DNA is packaged together with structural proteins (histones) to form a supramolecular complex known as chromatin. Chromatin is arranged in repeating units, known as nucleosomes: each nucleosome is formed by a sequence of DNA wound around eight histone cores. Chromatin may have a condensed conformation, known as heterochromatin, is essentially transcriptionally repressed, or a decondensed conformation known as euchromatin, and is transcriptionally active. The regulation of chromatin conformation is a fundamental biologic process and regulates, at specific sites, accessibility to DNA, a step required to allow gene transcription, replication, recombination, and DNA repair. Epigenetic mechanisms determine heritable changes in gene expression that are due to alterations in the DNA sequence. Various epigenetic mechanisms play an essential role in the control of chromatin conformation, and are mainly represented by posttranslational modifications of histone, adenosine triphosphate (ATP)-dependent nucleosome remodeling, DNA modifications, and replacement of histone with histone variants. Posttranslational modifications of histones 
represent one of the main epigenetic mechanisms to control gene expression.

Histones are highly basic nuclear proteins. They represent spools around which DNA winds, and play an essential role in the control of gene expression. ${ }^{1-3}$ There are five main families of histones: H1/H5, H2A, H2B, H3, and H4. H1/H5 are known as linker histones, while H2A, H2B, H3, and H4 are known as core histones. The linker histones bind the nucleosome at the entry and exit sites of the DNA, thus maintaining DNA in place. The core histones form dimers, and four dimers form one octameric nucleosome core. Each canonical histone protein - $\mathrm{H} 3, \mathrm{H} 4, \mathrm{H} 2 \mathrm{~A}$, and $\mathrm{H} 2 \mathrm{~B}$ - shares a common structural domain consisting of $3 \alpha$ helices $(\alpha 1, \alpha 2$, and $\alpha 3$ ), separated by two loops (L1 and L2) called the histone fold, facilitating the heterodimerization of $\mathrm{H} 2 \mathrm{~A}$ with $\mathrm{H} 2 \mathrm{~B}$ and $\mathrm{H} 3$ with $\mathrm{H} 4$. These heterodimeric interactions form the dimeric structural unit of nucleosomes. There are variants for the core histones $\mathrm{H} 3, \mathrm{H} 2 \mathrm{AB}$, and $\mathrm{H} 2 \mathrm{~B}$ : the histone variant $\mathrm{H} 3.3$ differs from the canonical histone $\mathrm{H} 3$ in five amino acids required for the genomic localization of $\mathrm{H} 3.3$ (usually $\mathrm{H} 3.3$ occupies gene promoters), and $\mathrm{H} 2 \mathrm{~A}$. $\mathrm{Z}$ has considerable amino-acid variation compared to $\mathrm{H} 2 \mathrm{~A}$.

Histone proteins undergo many modifications, mainly represented by lysine methylation, arginine methylation, arginine citrullination, lysine acetylation, and serine/threonine/ tyrosine phosphorylation. Each nucleosome is composed of a short segment of DNA of about 145-147 base pairs and is engulfed by a histone octamer core, consisting of four dimers of each core histone (H2A, H2B, H3, and H4). The core histone is essentially a globular structure, except for histone tails, composed of about 30 amino acids. These tails are modified by numerous posttranslational modifications, including methylation, phosphorylation, acetylation, ubiquitination, SUMOylation, ADP ribosylation, deamination, and crotonylation. These epigenetic, posttranslation modifications of histone are highly controlled, governed by three categories of enzymatic proteins: "writers" are involved in the addition of chemical groups to histone tails, "erasers" involved in the removal of these chemical groups, and "readers" are proteins that specifically recognize these histone modifications. Notable examples of writers are represented by histone acetyltransferases (HATs) and histone methyltransferases, while erasers are represented by histone deacetylases and lysine demethylases; examples of readers are given by bromodomain-containing proteins, methyl-lysine and methyl-arginine-binding domain-containing proteins and PDH-containing proteins.

Histone acetylation is a dynamic process regulated by two families of enzymes: HATs and histone deacetylases
(HDACs). ${ }^{4}$ HATs catalyze the transfer of an acetyl group to the $\varepsilon$-amino group of lysine side chains of the histone protein; these enzymes use acetyl-CoA as a cofactor. This reaction determines the shift of lysine from positively charged to a more neutral condition, reducing the affinity of the histone tail protruding from the nucleosome. As a consequence of these changes, chromatin adopts a more relaxed structure, more suitable for transcriptional activity through the binding of transcription machinery. Particularly, the BET proteins BRD2, BRD3, and BRD4 recognize and bind to the acetylated histone-lysine residues. HDACs act in an opposite way, removing the acetyl groups from histone lysines. HATs comprise many enzymes, including CREBBP (CBP), EP300 (p300), KAT2B (PCAF), KAT5 (Tip60), and KAT6A (Mo2); HDACs include HDAC1-11 and SIRT1-7.

Histone methylation is a very important biologic process through which the expression of many genes is controlled. Histones can be methylated at the level of either lysine or arginine residue. ${ }^{5}$ Lysine residue can be monomethylated, demethylated, and trimethylated. Arginine residues can be monomethylated or demethylated. Methylation is a dynamic process. Methyl units to histone molecules are added by $S$-adenosyl-L-methionine (SAM)-dependent methyltransferase and erased by specific demethylases represented by flavin-dependent LSD1 (also known as KDM1A) and LSD2 (also known as KDM2A) or by the Jmj family of 2-oxoglutarate-dependent demethylase. ${ }^{5}$

Histone-lysine methylation can lead either to transcriptional activation or transcriptional repression. Methylation of histone $\mathrm{H} 3 \mathrm{~K} 4, \mathrm{H} 3 \mathrm{~K} 36$, and $\mathrm{H} 3 \mathrm{~K} 79$ is associated with transcriptional activation, while demethylation and trimethylation of $\mathrm{H} 3 \mathrm{~K} 9$ and $\mathrm{H} 3 \mathrm{~K} 27$ are associated with transcriptional repression. Methylation at specific lysine residues is catalyzed by specific methyltransferases: $\mathrm{H} 3 \mathrm{~K} 4$ methylation is catalyzed by the SET domain-containing methyltransferases MLL1 (KMT2A) and MLL2 (KMT2D), H3K79 is methylated by DOT1L, H3K27 methylation is catalyzed by EZH1 and EZH2, H3K36 methylation is performed by SETD2 and WHSC1, H3K9 methylation is induced by MECOM (EVI1) and PRDM16, and $\mathrm{H} 3 \mathrm{~K} 9$ dimethylation and trimethylation is induced by SUV39H1 and EHMT2. It is important to note that methylation occurring at the level of $\mathrm{H} 3 \mathrm{~K} 9$ and $\mathrm{H} 3 \mathrm{~K} 27$ represents the two main mechanisms of gene silencing in mammalian cells. EZH1 and EZH2 make up part of PRC2 in association with two other subunits: EED and SUL12.

It is important to point out that in addition to epigenetic modifications of histone, the epigenetic modification of DNA through methylation represents another key mechanism of gene regulation. ${ }^{6}$ DNA methylation is associated with 
transcriptional repression and occurs at the level of the $\mathrm{C}_{5}$ carbon of cytosine in DNA to form 5-methylcytosine $(5-\mathrm{mC})$, through a reaction catalyzed by three types of DNA methyltransferase: DNMT1, DNMT3A, and DNMT3B. TET enzymes (TET1, TET2, and TET3) promote the oxidation of 5 -mC to 5-hydroxymethylcytosine $(5-\mathrm{hmC})$, promoting the demethylation process. IDH1 and IDH2 enzymes catalyze the conversion from isocitrate to $\alpha$-ketoglutarate $(\alpha \mathrm{KG})$, which is required for the catalytic function of TET enzymes.

\section{Alterations in epigenetic modifiers in acute myeloid leukemia}

A considerable number of genetic studies have been performed in acute myeloid leukemia (AML), allowing identification of the most frequent genetic alterations observed in these leukemia types. Comprehensive whole-genome sequencing, exome sequencing, and targeted sequencing studies have shown that mutations at the level of the complex epigenetic gene machinery are frequent in AML. DNMT3A is mutated in $20 \%-25 \%$ of adult AML, and frequently involves the substitution of the amino acid arginine at position 882 . $D N M T 3 A$ mutation is frequently found in association with $F T_{3}{ }^{\mathrm{ITD}}, N P M 1, I D H 1$, and IDH 2 mutations. ${ }^{7} D N M T 3 A^{\mathrm{R} 882 \mathrm{H}}$ has dominant negative activity that markedly reduces DNA methylation. DNA hypomethylation is an initiating event in the development of DNMT3A-mutated AML and thus represents the cause and not the consequence of leukemia development. Furthermore, CpG-island hypermethylation, a phenomenon frequently observed in $D N M T 3 A^{\mathrm{WT}} \mathrm{AML}$, is dramatically reduced in DNMT3A-mutated AML. ${ }^{8}$ In line with these observations, conditional knock-in mice develop AML with enlarged hematopoietic stem-cell compartments and involvement of the mTOR pathway. Consequently, DNMT3A-mutated leukemic cells are sensitive to the mTOR inhibitor rapamycin. ${ }^{9}$ DNMT3A mutations occur during the preleukemic phase of AML pathogenesis, supporting the key role for aberrant DNA methylation and consequent epigenetic reprogramming in malignant transformation of hematopoietic cells. The presence of DNMT3A mutations in AML is associated with poor outcome and reduced survival. ${ }^{10,11}$ DNMT1 is not mutated in AML, but is frequently overexpressed. ${ }^{12}$ DNMT1, which methylates hemimethylated DNA, is involved in the differentiation of normal hemopoietic stem cells (HSCs) and maintenance of leukemic SCs through epigenetic silencing of genes that inhibit self-renewal and leukemogenesis. ${ }^{13}$ Recent research has suggested that DNMT1A could represent a therapeutic target for some AML. In fact, DNMT1A expression can be targeted in leukemic cells by inhibitors of FABP4 (upregulated in AML and stimulates DNMT1A expression in these cells) ${ }^{14}$ or by inhibitors of receptor tyrosine kinases. ${ }^{15}$ These treatments result in inhibition of tumor growth, induction of cell differentiation, and impairment of leukemic progress in leukemia animal models. ${ }^{14,15}$ Very interestingly, a recent study provided evidence that MUC1-C, a transmembrane oncoprotein aberrantly expressed in leukemic SCs (where it is coexpressed with DNMT1), drives DNMT1 transcription. ${ }^{16}$ Targeting MUC1-C with a specific monoclonal antibody, together with the DNMT1 inhibitor decitabine, markedly reduces DNMT1 expression and impairs the survival of AML cells. ${ }^{16}$

The ASXL1 gene encodes a chromatin-binding protein and is mutated in about $3 \%-5 \%$ of AML. The incidence of these mutations is higher in patients with intermediate risk and particularly with high-risk and secondary AML, where it is mutated in about $16 \%$ of patients. ASXL1 mutations, as a single prognostic factor, are associated with a negative outcome. ${ }^{17} \mathrm{ASXL1}$ gene mutations are particularly frequent $(20 \%)$ in $R U N X 1$-mutated $\mathrm{AML}^{18}$ and are often associated with myelodysplasia-related changes. ${ }^{19}$

EZH2, a catalytic component of PRC2, which mediates transcriptional silencing through di- and trimethylation of lysine 27 of histone $\mathrm{H} 3$, playing an important role as a histone-lysine $N$-methyltransferase enzyme, is mutated in about $2 \%$ of adult AML, where inactivating mutations are usually observed. ${ }^{20}$ Some AML displays a decrease in EZH2 protein levels due to a posttranslational mechanism triggered by EZH2 phosphorylation induced by CDK $1 .{ }^{21} \mathrm{EZH} 2$ inactivation is frequently observed at disease relapse, and is associated with $H O X$ gene derepression and resistance to multiple drugs. ${ }^{21} \mathrm{EZH} 2$ loss is frequently associated with a decrease in H3K27me3 levels. ${ }^{21}$ EZH 2 mutations are more frequent in RUNX1-mutated ${ }^{18}$ and secondary AML, and are often associated with increased HOXA9 expression. ${ }^{22}$

About $3 \%-5 \%$ of de novo AML patients display partial tandem duplication of the $M L L$ gene, which is characterized by internal tandem duplication of exons $3-9$ or $3-11 .^{23}$ $M L L^{\mathrm{PTD}}$ acts as an oncogene by upregulating the expression of $H O X$ genes. These AML types display frequent mutations of other epigenetic regulators, such as TET2 (16\%), EZH2 (10\%), IDH1/2 (31\%), and ASXL1 (6\%). Furthermore, a typical feature of $M L L^{\mathrm{PTD}}$ consists of the absence of NPMI mutations and frequent RUNX1 (23\%) and STAG2 mutations $(16 \%){ }^{23} B C O R$ is a component of the variant-group polycomb-repressive complex, mutated in about $4 \%$ of karyotype-normal AML. BCOR plays an important role in the control of hematopoiesis by inhibiting myeloid-cell proliferation and differentiation and regulates $H O X$ gene expression. $^{24}$ 
Interestingly, in a recent molecular classification of AML based on the analysis of a large set of samples, one of the largest groups was represented by AML with mutated chromatin, RNA-splicing genes or both, characterized by mutations of genes regulating chromatin ( $A S X L 1, S T A G 2, B C O R, M L L^{\mathrm{PTD}}$, and PHF6), RNA splicing (SRSF2,SF3B1,U2AF1, and ZRSR2), or transcription (RUNX1). ${ }^{25}$ As such, no single molecular lesion defines this group. Interestingly, overlapping patterns of comutations are observed among the defining genes of this AML group. ${ }^{25}$ It is important to note that as stated earlier, this AML subgroup also contains AML types with mutations of the splicing-factor machinery. Interestingly, mutations at the level of these genes interfere with premRNA splicing of genes that are involved in the epigenetic machinery, such as $B C O R, M L L 2$, and EZH2, and through this mechanism affect hematopoiesis. ${ }^{26,27}$ It is important to underline that most patients in the chromatin-spliceosome group were older, with lower white-cell and blast-cell counts and response rates and negative long-term clinical outcome. ${ }^{25}$ Therefore, it is evident that most of these patients must be classified as high-risk AML. ${ }^{28}$

About $3 \%$ of de novo adult AML harbors a translocation of the MLL1 gene fused to various partners, including AF4, AF9, ENL, AF10, ELL and AF6; secondary MLL-rearranged AML is observed in patients treated with topoisomerase inhibitors. ${ }^{29}$ These AML types have a negative prognosis, and are thus classified as high-risk AML. The main pathogenic mechanism of these AML types is related to the capacity of the MLL-fusion proteins to aberrantly regulate MLLtarget genes, such as $H O X A$ and MEIS1, and to modify the genetic program of proliferation and differentiation of HSC/HPC. ${ }^{30}$

TET2 is a protein that acts as an epigenetic modifier to convert methylcytosine to hydroxymethylcytosine. This protein is mutated in about $10 \%-20 \%$ adult $\mathrm{AML},{ }^{31}$ and its frequency is significantly higher in older AML patients. ${ }^{32}$ TET2 mutations in AML were not associated with distinct clinical or genetic features, except for $I D H$ mutations, which were almost mutually exclusive with TET2 mutations. ${ }^{33}$ At the clinical level, it is unclear whether the presence of TET2 mutations represents a factor affecting patient outcome. The mutation of such genes as TET2, IDH1, and IDH2 causes defective conversion of 5-methylcytosine to 5-hmC, impairing demethylation of DNA. Recent immunocytochemical and biochemical studies have shown that AML with TET2 mutations shows reduced 5-hmC levels; however, 5-hmC levels were not predictive of survival in AML patients with normal-karyotype AML. ${ }^{34,35}$ Importantly,
TET2 mutations are found also in the white blood cells of otherwise-normal adults with clonal hematopoiesis, a condition related to aging and associated with myeloid-lineage bias and increased risk of development of myelodysplastic syndrome (MDS) or AML. ${ }^{36}$ These observations have led to a hypothesis that TET2 mutations represent a preleukemic abnormality required for the initial steps of leukemic transformation, enabling disease progression. In line with this hypothesis, a recent study provided evidence that TET2 mutations are essential to induce the survival and aberrant self-renewal of leukemic SCs. ${ }^{37}$ Interestingly, vitamin C, able to enhance 5-hmC in TET2-deficient cells, drives DNA hypomethylation, induces the expression of a TET2-dependent gene signature, inhibits colony formation of TET2-mutated human leukemic cells, and blocks leukemia progression in primary leukemia patient-derived xenografts. ${ }^{37}$ Finally, vitamin C strongly synergizes with PARP inhibitors to induce the killing of TET2-mutated leukemic cells. ${ }^{37}$

The $\mathrm{NADP}^{+}$-dependent isocitrate dehydrogenases (IDH1 and IDH2) are critical metabolic enzymes involved in the interconversion of isocitrate to $\alpha \mathrm{KG}$. Recurrent somatic mutations of IDH1 occur in $6 \%-10 \%$ of adult AML cases: these mutations affect the arginine residue at position 132 or 170 . IDH2 mutations occur in $8 \%-12 \%$ of adult AML, affecting the arginine residue at position 140 or 172 . Leukemia-associated IDH1/IDH2 mutations confer the neomorphic activity of reducing $\alpha \mathrm{KG}$ to the oncometabolite 2-hydroxyglutarate. The accumulation of this oncometabolite inhibits $\alpha \mathrm{KG}$-dependent dioxygenases, including histone demethylases and methylcytosine dioxygenases of the TET family. ${ }^{38}$ The consequent epigenetic deregulation results in DNA and histone hypermethylation, altered gene expression, and blocked cell differentiation. ${ }^{28}$ The presence of $I D H$ mutations does not confer specific properties to leukemic cells, apart from $I D H 2^{172}$ mutations. In fact, $I D H 2^{172}$-mutant AML represents a subgroup of AML corresponding to about $1 \%$ of all AML types ${ }^{25}$ and displaying gene-expression and DNA-methylation profiles that differ from the profiles for other $I D H$ mutations, and display peculiar aberrations in metabolic activity. ${ }^{39,40}$ Specific inhibitors of mutant IDH1 and IDH2 enzymes have been developed and introduced into clinical trials. These inhibitors have demonstrated a remarkable single-agent activity in relapsed/refractory AML patients. Patients with relapsing/refractory IDH2-mutant AML displayed in $40 \%$ of cases a clinical response to treatment with enasidenib (AG221), an IDH2-mutant-specific inhibitor. Importantly, $19 \%$ of these patients achieved a complete response, with median survival of about 20 months. ${ }^{41}$ 
Interestingly, the responding patients displayed blast-cell leukemic-cell differentiation. ${ }^{41}$ Mutations of some genes involved in the epigenetic DNA machinery are frequent in AML, and among these mutations, TET2, ASXL1, and $D N M T 3 A$ are associated with reduced overall survival. ${ }^{42}$

In parallel with these observations, other studies have analyzed the occurrence of gene mutations in AML at the clonal level and during the history of disease (ie, at diagnosis and relapse). The results of these analyses have defined the clonal evolution of the AML process. The most relevant results of these studies showed that mutations in genes encoding epigenetic modifiers, such as DNMT3A, TET2, ASXL1, $I D H 1$, and $I D H 2$, were acquired during the early steps of leukemia development and were present in the founding clone, while other mutations, such as those involving NPM1, $F L T 3$, and $R A S$, were secondary events occurring at late steps of leukemic development. Importantly, these mutations of epigenetic modifiers are observed also in aging individuals in the context of clonal expansion of hematopoiesis, a preleukemic condition associated with an increased risk of developing leukemia. Furthermore, these mutations usually persist after therapy, lead to clonal expansion during remission, and contribute together with new mutations to disease relapse. ${ }^{43,44}$ The analysis of large sets of older people of different geographical regions without evidence of hematologic malignancies has confirmed a high incidence of clonal hematopoiesis ( $5 \%-10 \%$ at 70 years; about $20 \%$ at 90 years), and has shown that the most commonly mutated genes are DNMT3A, TET2, and ASXL1. ${ }^{45,46}$

Several recent studies have explored the pattern of epigenetic changes occurring in the various AML types and attempted to classify these leukemias according to this pattern and define possible associations between these epigenetic changes and patient outcome. Large-scale genome-wide DNA-methylation profiling has revealed the existence of distinct DNA-methylation patterns in AML, thus indicating that these leukemias are composed of epigenetically distinct diseases. ${ }^{47}$ Different cytogenetic and molecular AML subtypes were found to display different DNA-methylation profiles. ${ }^{47-50}$ AML characterized by specific translocation events, such as $\mathrm{t}(8 ; 21)$-AML1/ETO, inv(16)-t(16;16)-CBFB-MYH11, $\mathrm{t}(15 ; 17)-P M L-R A R \alpha$, and $\mathrm{t}(\mathrm{v} ; 11 \mathrm{q} 23)-\mathrm{MLL}$, was characterized by unique DNA-methylation signatures. ${ }^{47-50}$ The group of NPM1-mutated AML was heterogeneous for the methylation pattern: four methylation clusters were identified, one hypermethylated and three both hyper- and hypomethylated, ${ }^{47}$ this methylation heterogeneity seemingly reflecting the molecular heterogeneity of this karyotype-normal AML subgroup and dictated by the co-occurrence of DNMT3A, FLT3, and IDH1/IDH2 mutations. ${ }^{47,48}$ DNMT3A mutations and particularly $D N M T 3 A^{\mathrm{R} 882}$ mutations were associated with hypermethylation. ${ }^{51}$ TET2 and IDH1/IDH2 mutations were associated with a genome-wide hypermethylation signature, particularly pronounced for IDH1/IDH2-mutated AMLs. ${ }^{51,52}$

Various studies have supported a possible role of DNA methylation pattern as a prognostic index for predicting clinical outcome in AML patients. In this context, particularly interesting was a recent study by Luskin et al. These authors performed a multilocus DNA assessment using an xMELP assay and calculated a methylation statistic (M score), showing that: the $\mathrm{M}$ score was lower in patients surviving after 2 years compared to that observed in dead patients, and the same applies for complete remission; low-M-score AML patients had better overall survival than high-score patients; and the M score was not associated with established molecular markers, such as NPM1 and FLT3 ${ }^{\text {ITD }}$ mutations, but was clearly associated with mutations in DNMT3A and IDH1. ${ }^{53}$

In this context, $\mathrm{Li}$ et al explored epigenetic heterogeneity and possible links among genetic heterogeneity, genetics, and epigenetics in AML. ${ }^{54}$ They observed that the degree of methylation variation, defined as epiallele burden, at the same loci between samples represented a predictor of relapse risk among AML patients. Patients were subdivided according to the level of allelic burden, and those with high allelic burden relapsed more rapidly, compared with those with low epiallele burden. Importantly, the prognostic significance of the level of allelic burden was independent of cytogenetics and white-blood-cell counts at diagnosis. Comparison between AML blasts and normal bone-marrow cells showed that 100\% leukemic samples displayed epigenetic allele shifting compared to normal bone marrow. Furthermore, $92 \%$ of patients showed epigenetic allele shifting between diagnosis and relapse. Importantly, there was no link between epigenetic burden and mutation burden. Finally, there was no increase in genes that regulate methylation (DNMT1, DNMT3A, TET1, $T E T 2, I D H 1, I D H 2)$ in those samples with higher level of epiallele burden. ${ }^{54}$

Constant advancements in the identification of molecular abnormalities of AML has allowed the proposal of new classifications of AML neoplasia, encapsulating information on genetic abnormalities, morphology, immunophenotype, and clinical presentation. The first French-American-British classification defined eight AML subtypes (M0-M7) according to morphological and cytochemical features: M0 (undifferentiated acute myeloblastic leukemia), M1 (acute myeloblastic leukemia with minimal maturation), M2 (acute myeloblastic 
leukemia with maturation), M3 (acute promyelocytic leukemia [APL]), M4 (acute myelomonocytic leukemia), M4E (acute myelomonocytic leukemia with eosinophilia), M5 (acute monocytic leukemia), M6 (acute erythroid leukemia), and M7 (acute megakaryoblastic leukemia). In 2008, the World Health Organization (WHO) introduced a new classification based on the integration of molecular and cellular criteria. ${ }^{55}$ Finally, in 2016 a new revised updated version of the WHO classification of myeloid neoplasia was released. ${ }^{56}$

The integration of cytogenetic and molecular criteria allows the stratification of AML into three prognostic subgroups: 1) favorable prognosis for various AML subtypes identified according to the cytogenetic and molecular features $\mathrm{t}(8 ; 21)$ with no c-Kit mutations, inv(16), $\mathrm{t}(15 ; 17)$, mutated NPM1 without FLT3 ${ }^{\text {ITD }}$ (karyotype cytogenetically normal [CN]-AML), and mutated biallelic CEBPA (CN-AML); $2)$ intermediate prognosis, including $t(8 ; 21)$ with $\mathrm{c}-\mathrm{Kit}$ mutation, $t(9,11), \mathrm{CN}-\mathrm{AML}$ other than those included in the favorable or adverse prognostic group, and cytogenetic abnormalities not included in the favorable or adverse prognostic group; and 3) adverse prognosis, including TP53 mutation, regardless of cytogenetic profile, CN-AML with FLT3 ${ }^{\text {ITD; }}$ CN-AML with DNMT3A, CN-AML with $K T M 2 A^{\text {PTD }}$, inv(3), $\mathrm{t}(6,9),-5$, or $\operatorname{del}(5 \mathrm{q}),-7$, complex karyotype, and 11q abnormalities other than $\mathrm{t}(9 ; 11)$.

A recent study ${ }^{25}$ based on a very large set of primary adult AML $(1,540)$ patients proposed a detailed molecular classification of these neoplasia, with the identification of 13 subgroups:

- AML with NPM1 mutations (about 27\%), frequently displaying also DNMT3A, FLT3 ${ }^{\mathrm{ITD}}, N R A S$, and TET2 mutations

- AML with mutations in genes encoding chromatin, RNAsplicing genes, or both (about 18\%), including RUNX1, $M L L, S R S F 2, D N M T 3 A, A S X L 1$, and STAG2 mutations

- AML with TP53 mutations, chromosome aneuploidy, or both (about 13\%), including TP53 mutations, complex karyotype $-5 / 5 q,-7 / 7 q,-12 / 12 p$, and $+8 / 8 q$

- AML with inv(16) or t(16;16), CBFB-MYH11 (about 9\%)

- AML with biallelic CEBPA mutations (about 4\%)

- AML with t(15;17), PML-RAR $\alpha$ (about 4\%)

- AML with t(8;21)(q22;q22), AML1-ETO (about 4\%)

- AML with $M L L$ fusion genes, $\mathrm{t}(\mathrm{x} ; 11)(\mathrm{x} ; \mathrm{q} 23)$ (about 3\%)

- AML with iv(3) or t(3;3), GATA2, MECOM (about 1\%)

- AML with $I D H 2^{\mathrm{R} 172}$ mutations (about 1\%)

- AML with driver mutations, but no detected class-defining lesions (about 11\%), frequently displaying FLT3 $3^{\mathrm{ITD}}$ or DNMT3A mutations
- AML with no detected driver mutations (4\%)

- AML meeting criteria for multiple genomic subgroups $(4 \%)$.

Adult AML patients with AML usually receive a standard treatment based on 7 days of cytarabine and an anthracycline for 7 days. Using this standard treatment, some groups of AML patients have an approximate "cure" probability (favorable risk), whereas other groups have a survival comprised in a range of 6-18 months. First-generation epigenetic drugs, such as azacitidine and decitabine, currently used for the treatment of MDS, are also used for treating AML patients not eligible for treatment with intensive chemotherapy and with stem-cell transplantation. Under this epigenetic treatment, only $15 \%-20 \%$ of patients display a complete response. More recently, guadecitabine was introduced, a next-generation hypomethylating agent that is not metabolized by cytidine deaminase and the enzyme that degrades decitabine. A recent study showed that $>50 \%$ of treatmentnaïve AML patients $>65$ years old ( 77 years mean age) displayed a complete response to treatment with guadecitabine. ${ }^{57}$ Responding patients displayed a median survival $>500$ days, with an acceptable drug-related toxicity profile. Analysis of the various types of patients enrolled in this study provided evidence about the existence of genetic determinants underlying the response of AML patients to guadecitabine. Patients with $R A S$ and $I D H 2$ mutations had much less chance of getting a complete response to guadecitabine treatment than those without these mutations. In contrast, patients with mutations of other epigenetic regulators, such as $D N M T 3 A$, ASXL1, EZH2, TET2, U2AF1, or WT1, had a comparable chance of developing a complete response, as well as those with AML without these mutations. ${ }^{58}$ Furthermore, the frequency of complete responders was higher among patients with naïve AML (56\%) than those with relapsed-refractory AML (22\%). ${ }^{58}$ Although patients with relapsed-refractory AML displayed a lower rate of complete responses, responder patients displayed long-term survival, and their overall survival was significantly better than that observed for nonresponder patients. ${ }^{59}$ In the whole AML-treated population, $19 \%$ of patients survived after 2 years; median overall survival was 6.5 months among nonresponder patients and $>29$ months in responder patients. ${ }^{59}$ These results are encouraging, and strongly support the use of hypomethylating agents in older AML patients.

AML with TP53 mutation has a very negative prognosis; these leukemias are usually associated with adverse karyotypes and are more frequent among older AML patients. Welch et al treated 88 AML patients with a 10-day regimen of decitabine and reported high rates of morphological 
remission (46\%). ${ }^{60}$ Interestingly, they noted higher response rates among AML patients with an unfavorable cytogenetic profile than among those with intermediate or favorable cytogenetic profiles (67\% versus 37\%) and among patients with TP53 mutations compared to those without TP53 mutations (100\% versus $41 \%$ ).

Two recent studies have explored the clinical activity of guadecitabine in high-risk myelodysplasia patients refractory or relapsing after azacitidine and observed only modest response rates. ${ }^{61}$ The second study explored a population of untreated high-risk myelodysplasia, and provided evidence that guadecitabine was active in this set of patients (with $28 \%$ complete responses), even in patients with adverse biologic features, such as high frequency of complex karyotype, therapy-related disease, and TP53 mutations. ${ }^{62}$ Targeting epigenetic abnormalities could represent a potentially promising strategy for the development to innovative AML treatments. Here, we analyze some epigenetic modifiers and their inhibitors, focusing on those that have reached the first stages of clinical trials in AML.

\section{LSD I}

\section{Structure and function}

Histone methylation is a dynamic process. Histone lysine and arginine residues are $\mathrm{N}$-methylated at the level of H4; some nonhistone proteins, such as p53, can be also methylated. The effect of methylation on gene transcription is variable in that it can result either in induction or repression of gene transcription, depending on the extent of methylation and the position of the methylated residue. Therefore, examples of methylation typically associated with active gene expression are given by methylation of lysine 4 or 36 of histone $\mathrm{H} 3$, while examples of repressive methylation are represented by methylation of lysine 9 or 27 of histone H3. The combination of all the histone-modification events, including methylation, acetylation, phosphorylation, and ubiquitination, determine the final chromatin conformation and the transcriptional activation of a given gene. More than 20 lysine demethylases have been discovered, pertaining to two main gene families: the KDM1 subfamily containing the LSD enzymes and the KDM2-KDM7 subfamilies, consisting of JmjC-containing enzymes. The KDM1 LSDs are mainly represented by LSD1 and LSD2, which are flavin-dependent amine oxidases related to monoamine and polyamine oxidases: these enzymes are dependent on a single electron pair within the lysine for catalysis and consequently can demethylate only mono- and dimethylated lysines. In contrast, JmjC KDMs are $\mathrm{Fe}^{2+}$ - and 2-oxoglutarate-dependent deoxygenases capable of demethylating mono-, di-, and trimethylated lysines. LSD1 is specifically involved in the demethylation of monomethylated and dimethylated lysine 4 residues on histone 3 . LSD1 can demethylate the lysine residues also of some nonhistone proteins, such as p53 and DNMT1. LSD1 can also methylate $\mathrm{H} 3 \mathrm{~K} 9$ when it is complexed with the androgen receptor. ${ }^{63}$ LSD2 specifically demethylates histone H3K4 me1-2 inside areas of its target genes.

The molecular structure of LSD1 and LSD2 proteins has been determined. LSD2 is a homologue of LSD1 based on its sequence, and shares about $30 \%$ sequence similarity with LSD1. Several structural/functional domains have been characterized. Some of these domains are present in both LSD1 and LSD2 proteins: an AOL domain, essential for enzymatic activity (the AOL domain has two lobes, one forming a noncovalent FAD-binding site and the other a substrate-binding and -recognition site), and a SWIRM domain, typically observed in chromatin-associated proteins (the SWIRM domain is involved in protein-protein interactions; it is also involved in the association with the androgen receptor). Other domains are specific to LSD1, such as the TOWER domain, while others are specific to LSD2, such as the amino zinc-finger domain, whose function is unclear (Figure 1). ${ }^{64}$ As mentioned, the catalytic activity of both LSD1 and LSD2 enzymes is in the AOL domain and requires the cofactor FAD.

The determination of the three-dimensional structure of LSD1 considerably helped in the understanding of the function of this protein at the molecular level. LSD1 forms a highly symmetric, packed domain structure from which a long helical tower domain protrudes. The SWIRM domain, which contributes to the stability of the protein, packs together with the AOL domain through numerous interactions. The active site cavity present at the level of the AOL domain is spacious and capable of accommodating several residues of the histone-tail substrate..$^{65,66}$

The chemical demethylation reaction catalyzed by LSD1 is complex. During all the reactions catalyzed by LSD1, at each demethylation cycle a molecule of formaldheyde and $\mathrm{H}_{2} \mathrm{O}_{2}$ is produced and $\mathrm{O}_{2}$ is consumed. The chemical reaction involves the initial conversion of methylated lysine to an iminium cation by loss of a hydride anion captured by the oxidized FAD prosthetic groups (Figure 1). The imine cation is then hydrolyzed to produce a carbinol amine, decomposing to formaldehyde, and the demethylated residue. The reduced FAD produced during the initial step of the reaction is reoxidized by $\mathrm{O}_{2}$ to generate a molecule of $\mathrm{H}_{2} \mathrm{O}_{2}$ and regenerated oxidized FAD (Figure 1). ${ }^{67,68}$

The capacity of LSD1 to form molecular complexes with other nuclear proteins and transcriptional factors is an 


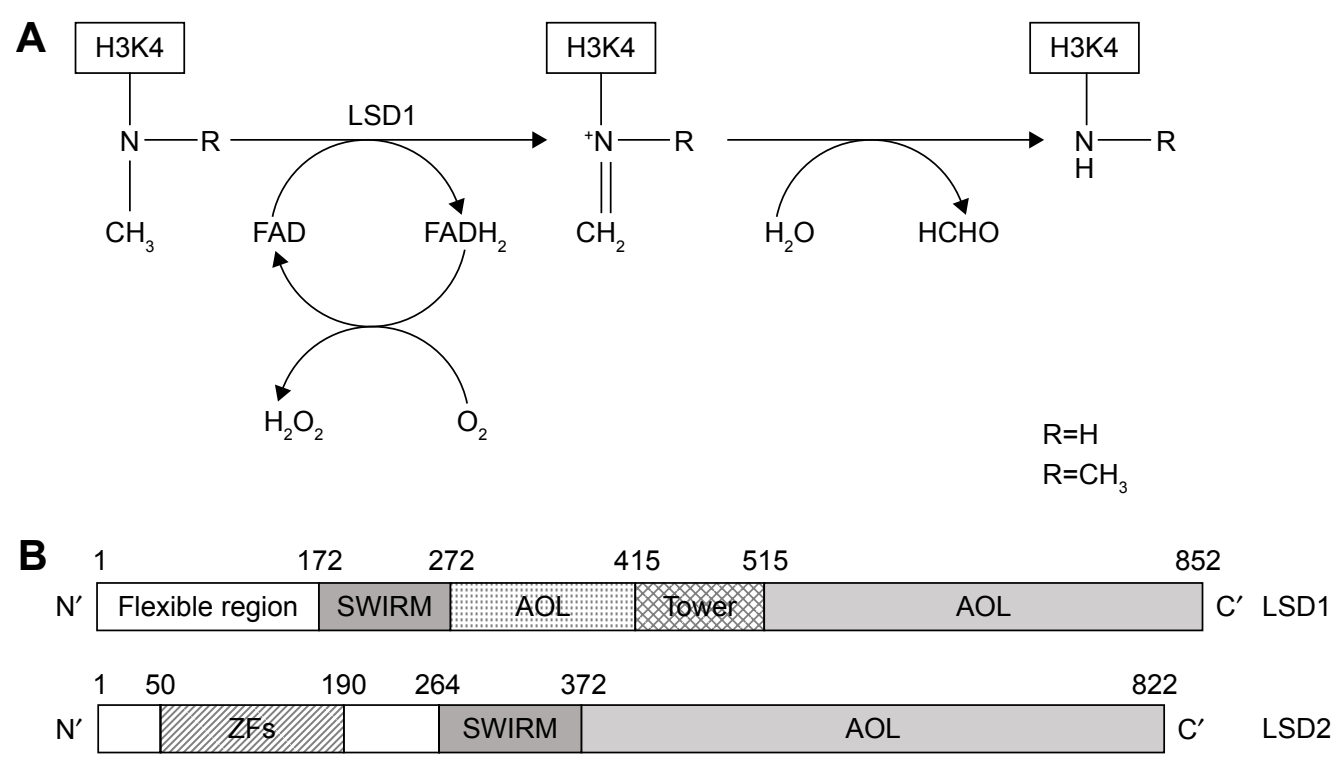

Figure I Schematic representation of enzymatic activity and linear structure of human LSDI and LSD2.

Notes: (A) Enzymatic reaction catalyzed by LSDI. LSD I catalyzes the demethylation of Lys 4 of histone H3 (H3K4) through a flavin-dependent oxidative reaction. LSDI acts on both di- and monomethylated $\mathrm{H} 3 \mathrm{~K} 4$. The reaction involves the steps shown from the left to right: first, the histone substrate is bound by the enzyme and the methylated Lys4 side chain is oxidized by the FAD prosthetic group, with consequent reduction of oxygen $\left(\mathrm{O}_{2}\right)$ to hydrogen peroxide $\left(\mathrm{H}_{2} \mathrm{O}_{2}\right)$; second, the resulting imine intermediate is then hydrolyzed, thus generating the demethylated $\mathrm{H} 3$ tail and formaldehyde. (B) Overview of LSDI and LSD2 structure. Human LSDI is composed of 852 amino acids with major domains: an N-terminal SWIRM (small $\alpha$-helical domain), contributing to the steadiness of the molecule; a central protruding Tower domain; and a C-terminal amine oxidase like (AOL) domain. Among these domains, the AOL and SWIRM domains pack together through various interactions (at the level of three-dimensional structure), determining the formation of a spherical structure. At the level of the N-terminal (I-172), there is an N-flexible region. Human LSD2 is composed of 822 amino acids and displays $31 \%$ of sequence similarity with LSDI. LSD2 shows three major domains, from the $\mathrm{N}$ - to the C-terminal: a ZFs area, a SWIRM, and an AOL domain. It is important to note that LSD2 does not contain a Tower domain, the structure of which plays a crucial role in LSDI for CoREST binding.

essential property of its activity and the regulation thereof. In this context, it is important to point out that LSD1 was initially discovered as a molecular partner of HDAC2 in HeLa cells. ${ }^{69}$ Subsequently, many other studies have shown that LSD1 participates in the formation of multisubunit complexes involving LSD1, CoREST (also known as RCOR1), HDAC1, HDAC2, ZNF217, PHF21A and HMG20B. This complex is commonly known as the CoREST transcriptionrepressor complex. ${ }^{70,71}$ The functional implications of all these interactions are not completely defined. However, the LSD1-CoREST interactions are required to protect LSD1 from proteosomal degradation, while the association with HDAC1/HDAC2 is required for both demethylase and HDAC activity. ${ }^{72}$ The molecular protein complex formed by LSD1 was covered in two recent reviews on LSD1. . $^{737}$

The LSD1 gene contains 19 exons, highly conserved among vertebrates. Through a process of alternative RNA splicing, two additional exons, E2a and E8a, can be included into mature mRNA and generate four possible LSD1 isoforms, called LSD1, LSD1-2a, LSD1-8a, and LSD1-2a+8a. ${ }^{75}$ The inclusion of exon E2a can occur in all tissues, while LSD1 transcripts containing E8a are found only in brain and testis. ${ }^{73}$ While insertion of the 60-nucleotide-long E2a exon does not modify the enzymatic activity of LSD1, insertion of the 12-nucleotide-long exon E8a could modify LSD1 enzymatic activity (in fact, the LSD1-8a isoform plays a role in mediating $\mathrm{H} 3 \mathrm{~K} 9$ and $\mathrm{H} 4 \mathrm{~K} 20$ demethylation).

\section{Role of LSDI in normal hematopoietic differentiation}

Gene-knockout studies have contributed greatly to our understanding of the role of LSD1 in the control of normal hematopoiesis. Conditional knockout studies have shown that a deficit of LSD1 expression in the hematopoietic system determines an expansion of HSCs and hematopoietic progenitor cells (HPCs) not associated with a significant increase in marrow cellularity and only a slight increase in white blood cells. ${ }^{76}$ Analysis of bone marrow of LSD1deficient animals showed an inhibition of granulopoiesis and a stimulation of monocytopoiesis, thus suggesting that LSD1 plays an important role in lineage choice during granulo/monocytic differentiation. ${ }^{76}$ Analysis of erythroidcell lineage has shown that LSD1 knockdown results in anemia associated with perturbed terminal erythropoiesis and expansion of early erythroid progenitors. ${ }^{70}$ Other studies have supported the role of LSD1 as an indispensable epigenetic governor of hematopoietic differentiation. ${ }^{77}$ This function is mainly exerted through the capacity of LSD1 to 
repress hematopoietic stem and progenitor gene-expression programs during hematopoietic cell differentiation. ${ }^{77}$ Deficient LSD1 expression causes a failure to silence HSC and HPC genes fully, compromising the different steps of the hematopoietic differentiation-cell program. ${ }^{77}$

The activity of LSD1 during hematopoietic differentiation and its regulatory effects on hematopoiesis are regulated by its interaction with CoREST/REST (Rcor) corepressors. Upadhyay et al showed that the three Rcor proteins (Rcor1, Rcor2, and Rcor3) regulate LSD1 activity and cellular differentiation in hematopoietic cells. All the three Rcor proteins interact with LSD1 and the transcription factor Gfilb: while Rcor1 and Rcor2 facilitate LSD1-mediated nucleosome demethylation, Rcor3 inhibits demethylation. ${ }^{78}$ In line with these observations, Rcor1 and Rcor2 favor differentiation, while Rcor3 inhibits differentiation. ${ }^{78}$ Rcor 1 and Rcor3 levels are differentially regulated in erythroid and megakaryocytic cells during terminal stages of maturation. ${ }^{78}$

The capacity of LSD1 to interact with some transcription factors acting as key master regulators of hematopoiesis is essential to explain its effects on hematopoietic differentiation. In hematopoietic cells, LSD1 and Rcor1 associate with Gfil and Gfilb and repress most Gfilb targets in erythroid cells. ${ }^{79}$ Gfi-transcription factors are master regulators of hematopoietic cell differentiation: Gfi1 is essential for neutrophil differentiation, while Gfilb is required for the development of erythroid and megakaryocytic lineages. ${ }^{80}$ Furthermore, LSD1-Rcor1 also associates with other transcription factors, such as Scl1/Tal1, ${ }^{81,82} \mathrm{Bcl11} \mathrm{A},{ }^{83}$ and GATA2 ${ }^{84}$ in erythroid cells, inducing repression of their target genes. The excessive and uncoordinated function of all these transcription factors induced by LSD1 deficiency in HPCs determines a derangement of erythroid and megakaryocytic cell differentiation. The interaction between Gfil and LSD1 involves the SNAG domain of Gfil: this domain needs to be methylated at the level of lysine 8 for optimal binding capacity to LSD $1 .{ }^{85}$

Finally, recent studies provided evidence that LSD1 plays a relevant functional role at the level of events that determine the initial specification of hematopoietic cell lineage during embryonic development. In vertebrates, the initial appearance of HSCs with long-term repopulation and multilineage-differentiation capacities occurs at the level of the aorta-gonad-mesonephros region. This primitive population of HSCs is generated from a rare subpopulation of endothelial cells, known as hemogenic endothelia and is capable of transdifferentiation through a process of endothelial to hematopoietic transition. This unique transdifferentiation process requires a molecular orchestration requiring from one side the repression of the endothelial differentiation program and from the other side the induction of the hematopoietic differentiation program. Gfil and Gfilb proteins mark the hemogenic endothelia, and are strictly required for the hemogenic activity of the hemangioblasts: the Gfi proteins, through the recruitment of LSD1 protein, exert their repressive effects on the endothelial differentiation program. ${ }^{86}$ Furthermore, LSD1 activity in the hemangioblast is essential for the inhibition of the endothelial differentiation program through downregulation of the transcription factor Etv2, an essential regulator of vasculogenesis. ${ }^{87}$

Gfi1 and Gfi1B act as transcriptional repressors by recruiting histone-modifying enzymes to promoters and enhancers of target genes, and thus can be considered epigenetic regulators that modify chromatin structure. Several rare hematological diseases are associated with acquired or inheritable mutations in the GFII and GFIIB genes; particularly, some patients with severe congenital neutropenia carry mutations in GFII that determine the disruption of the C-terminal zinc-finger domains. ${ }^{88}$ Furthermore, recent studies have suggested a possible role of GFil in human leukemias. Hones et al analyzed a large number of AML samples for GFil expression, showing that about $10 \%$ of these expressed low GFi1 levels. ${ }^{89}$ These leukemia types have a poor outcome and frequently display an adverse cytogenetic FABM0 phenotype, NRAS mutations, elevated EVI1 expression, and a leukemic stem-cell signature at the level of the gene-expression profile. ${ }^{83}$ In experimental mouse models, low GFi1 expression accelerates leukemia development driven by oncofusion proteins, such as MLLAF9. ${ }^{89}$ Low GFil confers sensitivity of leukemic cells to histone methyltransferase inhibitors, associated with resistance to HDAC inhibitors. ${ }^{89}$ Recently, Volpe et al analyzed AML with normal karyotype for GFil expression and observed that those displaying high expression of this transcription factor have frequent $F L T 3^{\text {ITD }}$ and NPM1 mutations, display an FLT3 ${ }^{\mathrm{ITD}}$ signature, and exhibit high expression of some leukemia-related genes, such as $H O X A 9$, MEIS1, and $P B X 3 .{ }^{90}$ At variance with the findings of Hönes et $\mathrm{a}^{89}$ obtained in the whole AML population, in karyotype-normal AML, high GFil expression was associated with a worse outcome. ${ }^{90}$

Very interestingly, mice deleted for Rcor1 were shown to be markedly anemic, showing a block of erythroid precursors at the transition from proerythroblasts to basophilic erythroblasts. ${ }^{91}$ Erythroid progenitors purified from Rcor1null bone marrow cultured in vitro form myeloid colonies, but fail to form erythroid colonies; ${ }^{91}$ mutant proerythroblasts 
aberrantly express genes typically expressed in myeloid cells and in SCs/PCs. ${ }^{91}$ Evaluation of the myelomonocytic lineage of $\mathrm{Rcor}^{-/-}$animals showed absence of mature neutrophils associated with an increase in monocytes, a feature observed also in $\mathrm{LSD}^{-/-}$mice. ${ }^{92}$

\section{LSDI in leukemia}

LSD1 is not mutated in acute leukemias or in other blood neoplastic disease. However, LSD1 is overexpressed in many hematologic diseases, including AML, acute lymphoblastic leukemia (ALL), myeloproliferative neoplasms, chronic myelomonocytic leukemia, and MDS. ${ }^{93}$ In AMLs, LSD1 was overexpressed in about $60 \%$ of cases. ${ }^{93}$

Using a model of human MLLAF9 leukemia, Harris et al identified LSD1 as a key regulator of leukemic stem-cell potential, in that this demethylase acts at the level of the genomic loci bound by MLLAF9, favoring the effect of the MLL-fusion protein and thus preventing cell differentiation and apoptosis. ${ }^{94}$ In line with this finding, primary AML cells bearing various MLL rearrangements were shown to be markedly inhibited by small-molecule LSD1 inhibitors. ${ }^{94}$ Interestingly, LSD1 was expressed in MLL-rearranged AML, as well as in other molecular subtypes of AML. In addition to MLL-rearranged AML, AML associated with PML-RARA and RUNX1-RUNX1T1 was shown to be sensitive to the LSD1 inhibitors. ${ }^{94}$ Consistent with these findings, LSD1 was found among the 5\% most highly expressed genes in prospectively purified immunophenotypic leukemic SCs from a variety of distinct AML subtypes. ${ }^{95}$

According to these observations, elevated LSD1 expression in AML and in other hematological neoplasia may contribute to leukemia development. To test this hypothesis, Wada et al evaluated the effect of LSD1 overexpression in HSCs and HPCs by generating transgenic mice that overexpress LSD1 in HSCs/HPCs under control of the Sca1 promoter. ${ }^{96}$ First, these authors showed that among acute leukemias LSD1 is expressed at the highest levels in T-cell ALL. ${ }^{88}$ The overexpression of the short LSD1 isoform, which lacks E2a and E8a, induced a marked increase in the selfrenewal activity of HSCs via upregulation of $H O X A$ genes, but retained multidifferentiation capacities. Transgenic mice overexpressing LSD1 did not develop any hematological neoplasia; however, these mice developed high frequency T-cell ALL after $\gamma$-irradiation. ${ }^{96}$

Schenk et al explored the capacity of LSD1 inhibitors to confer to non-APL cells the capacity to differentiate in response to all-trans retinoic acid (ATRA). In fact, while APL cells have the remarkable property to differentiate under treatment with ATRA, non-APL cells fail to undergo differentiation. Schenk et al showed that non-APL cell lines, as well as primary AML cells, undergo granulocytic differentiation when incubated with ATRA and an LSD1 inhibitor. ${ }^{97}$ Analysis of leukemic cells treated with LSD1 inhibitors showed that these drugs did not lead to a large-scale increase of $\mathrm{H} 3 \mathrm{~K} 4 \mathrm{me}$ across the genome, but increased $\mathrm{H} 3 \mathrm{~K} 4 \mathrm{me}$ and gene expression at the level of selected genes, particularly some genes involved in myeloid differentiation. ${ }^{97}$

\section{LSDI inhibitors}

The development of specific LSD1 inhibitors has been the objective of many recent studies. These inhibitors represent a fundamental tool to improve our understanding of the role of LSD1 in normal and pathological conditions, and offer a unique strategy to develop preclinical studies to evaluate the therapeutic impact of LSD1 inhibition in animal models of various pathologic conditions and to translate these studies in the clinic.

Some recent papers have analyzed in detail the structure and mechanism of action of the main LSD1 inhibitors that have been developed in the last 10 years. ${ }^{95}$ Here, we analyze the main LSD1 inhibitors and particularly those under clinical development, with emphasis on studies focused on AML treatment (Table 1). According to Niwa and Umehara, LSD1 inhibitors can be subdivided into two main groups: irreversible covalent inhibitors and reversible noncovalent inhibitors. ${ }^{98}$ The irreversible covalent inhibitors can be subdivided into three subgroups: (士)-trans-2-phenylcyclopropylamine (2-PCPA), $N$-alkylated 2-PCPA derivatives, and inhibitors other than 2-PCPA derivatives.

Studies on the MAO inhibitor tranylcypromine have led to the discovery that this compound exhibited better LSD1inhibitory activity than the other MAO inhibitors known at the time. ${ }^{99}$ It is important to briefly discuss the properties of Tranylcypromine (TCP), the compound initially investigated for its capacity to inhibit LSD1. TCP was approved as a drug for the treatment of depression. In combination with ATRA, TCP is under exploration in three clinical trials in AML patients: TCP in combination with ATRA in AML patients who cannot undergo chemotherapy (NCT02261779), TCP at four doses $(10,20,40$, and $60 \mathrm{mg})$ in combination with ATRA in AML and MDS patients (NCT02273102), and TCP in combination with ATRA and the chemotherapy agent cytarabine (DRKS00006055) (Table 1).

The 2-PCPA scaffold represents the basic structure used for the development of the large majority of irreversible LSD1 inhibitors. ${ }^{100}$ The introduction of various chemical 
Table I Main LSDI inhibitors introduced into a plan of clinical development

\begin{tabular}{|c|c|c|c|c|c|}
\hline Trial identifier & Title & Disease & Phase & Epigenetic drug & End points \\
\hline $\begin{array}{l}\text { EUDRACT } \\
2013-002447-29\end{array}$ & $\begin{array}{l}\text { A Phase I study of human } \\
\text { pharmacokinetics and safety of } \\
\text { ORYI00I, an LSDI inhibitor, } \\
\text { in relapsed or refractory acute } \\
\text { leukemia (AL) }\end{array}$ & $\begin{array}{l}\text { Acute myeloid } \\
\text { leukemia }\end{array}$ & $\mathrm{I} / \mathrm{II}$ & $\begin{array}{l}\text { ORYI00I (RG60I6) } \\
\text { (Oryzon Genomics } \\
\text { Barcelona, Spain) }\end{array}$ & $\begin{array}{l}\text { Safety, tolerability, pharmacokinetics, } \\
\text { pharmacodynamics, effects on cell } \\
\text { differentiation, clinical response in } \\
\text { acute myeloid leukemia subtypes }\end{array}$ \\
\hline NCT029I3443 & $\begin{array}{l}\text { A dose-finding and -expansion } \\
\text { study of RO705 } 1790 \\
\text { administered orally in patients } \\
\text { with relapsed, extensive-stage } \\
\text { disease small-cell lung cancer } \\
\text { (ED SCLC) }\end{array}$ & Small-cell lung cancer & I & $\begin{array}{l}\text { ORYI00I (RG60I6) } \\
\text { (Oryzon) }\end{array}$ & $\begin{array}{l}\text { Safety, tolerability, recommended } \\
\text { dose for Phase II, overall survival }\end{array}$ \\
\hline NCT02034I 23 & $\begin{array}{l}\text { Investigation of GSK2879552 in } \\
\text { subjects with relapsed/refractory } \\
\text { small-cell lung carcinoma }\end{array}$ & Small-cell lung cancer & I & $\begin{array}{l}\text { GSK2879552 } \\
\text { (GlaxoSmithKline } \\
\text { Philadelphia, PA, USA) }\end{array}$ & $\begin{array}{l}\text { Safety, tolerability, pharmacokinetics, } \\
\text { pharmacodynamics, recommended } \\
\text { dose for Phase II, clinical activity }\end{array}$ \\
\hline NCT02I778I2 & $\begin{array}{l}\text { A Phase I dose-escalation study } \\
\text { of GSK2879552 in subjects } \\
\text { with relapsed/refractory acute } \\
\text { myeloid leukemia (AML) }\end{array}$ & $\begin{array}{l}\text { Acute myeloid } \\
\text { leukemia }\end{array}$ & I & $\begin{array}{l}\text { GSK2879552 } \\
\text { (GlaxoSmithKline) }\end{array}$ & $\begin{array}{l}\text { Safety, tolerability, pharmacodynamics, } \\
\text { pharmacokinetics, recommended } \\
\text { dose for Phase II, clinical activity }\end{array}$ \\
\hline NCT027I 2905 & $\begin{array}{l}\text { An open-label, dose-escalation/ } \\
\text { dose-expansion safety study of } \\
\text { INCB059872 in subjects with } \\
\text { advanced malignancies }\end{array}$ & Advanced cancer & $\mathrm{I} / \mathrm{II}$ & $\begin{array}{l}\text { INCB059872 (Incyte, } \\
\text { Palo Alto, CA, USA) }\end{array}$ & $\begin{array}{l}\text { Safety, tolerability, tumor-response } \\
\text { rates, pharmacokinetics }\end{array}$ \\
\hline NCT03।32324 & $\begin{array}{l}\text { A study to evaluate safety, } \\
\text { pharmacokinetic, and biological } \\
\text { activity of INCB059872 in } \\
\text { subjects with sickle-cell disease }\end{array}$ & Sickle-cell disease & I & INCB059872 (Incyte) & $\begin{array}{l}\text { Safety, tolerability, pharmacodynamic } \\
\text { parameters (fetal hemoglobin levels) }\end{array}$ \\
\hline NCT03।36I85 & $\begin{array}{l}\text { IMG7289 in patients with } \\
\text { myelofibrosis }\end{array}$ & $\begin{array}{l}\text { Primary myelofibrosis } \\
\text { postpolycythemia } \\
\text { and post-essential } \\
\text { thrombocythemia } \\
\text { myelofibrosis }\end{array}$ & I & $\begin{array}{l}\text { IMG7289 } \\
\text { (Imago Biosciences, } \\
\text { San Francisco, CA, } \\
\text { USA) }\end{array}$ & $\begin{array}{l}\text { Safety, tolerability, pharmacokinetic } \\
\text { studies }\end{array}$ \\
\hline NCT02842827 & $\begin{array}{l}\text { IMG7289, with and without } \\
\text { ATRA, in patients with } \\
\text { myelofibrosis }\end{array}$ & $\begin{array}{l}\text { Acute myeloid } \\
\text { leukemia } \\
\text { myelodysplastic } \\
\text { syndromes }\end{array}$ & I & $\begin{array}{l}\text { IMG7289 } \\
\text { (Imago Biosciences) }\end{array}$ & $\begin{array}{l}\text { Safety, tolerability, pharmacokinetic, } \\
\text { and pharmacodynamic effects of } \\
\text { IM7289 with or without ATRA }\end{array}$ \\
\hline NCT02875223 & $\begin{array}{l}\text { A safety and efficacy study } \\
\text { of CC900II in subjects with } \\
\text { relapsed and/or refractory solid } \\
\text { tumors and non-Hodgkin's } \\
\text { lymphomas }\end{array}$ & $\begin{array}{l}\text { Non-Hodgkin's } \\
\text { lymphoma neoplasms }\end{array}$ & I & $\begin{array}{l}\text { CC900II (Celgene, } \\
\text { Summit, NJ, USA) }\end{array}$ & $\begin{array}{l}\text { Safety, tolerability, } \\
\text { pharmacokinetics, clinical response }\end{array}$ \\
\hline
\end{tabular}

Abbreviation: ATRA, all-trans retinoic acid.

modifications to this basic structure has led to the identification of many new compounds, some exhibiting higher LSD1-inhibitory activity and a reduced MAO-inhibitory activity ${ }^{98}$ Particularly, chemical substitutions on the phenyl ring of tranylcypromine have considerably improved the potency and selectivity of these LSD1 inhibitors. ${ }^{99}$

Most LSD1 inhibitors under clinical development pertain to the family of $\mathrm{N}$-alkylated 2-PCPA derivatives. This category of compounds was discovered by Oryzon Genomics (Barcelona, Spain), showing that LSD1 inhibition is markedly improved by the development of $N$-alkylated 2-PCPA derivatives, exhibiting LSD1-inhibitory potency in the nanomolar range. One of these compounds, ORY1001, displayed potent LSD1-inhibitory activity $\left(\mathrm{IC}_{50}\right.$ of about $18 \mathrm{nM})$ and specificity (>1,000-fold selectivity over MAOs and LSD2). ${ }^{97} \mathrm{~A}$ cellular assay on the THP1 cell line (MLL - AF9 cells) displayed pharmacologic activity of ORY1001 (as evaluated by methylation and cell differentiation assay) at subnanomolar concentrations. ${ }^{100}$ Leukemic cells with MLL translocations were particularly sensitive to the inhibitory effects of this compound. Daily oral doses $<20 \mu \mathrm{g} / \mathrm{kg}$ have shown a potent antileukemic effect in mice transplanted with MV $(4 ; 11)$ cells. ${ }^{100}$ Finally, preclinical pharmacologic and toxicologic studies showed 
good oral bioavailability and a good safety profile. ${ }^{101}$ Given this favorable pharmacologic profile, ORY1001 entered a plan of clinical development screening to investigate its safety profile and possible antitumor effects in patients with non-small-cell lung cancer and AML (Table 1).

A preliminary report on the ongoing Phase I/II clinical study on AML patients (EUDRACT 2013-002447-29) was presented at the last meeting of the American Society of Hematology in December 2016. Patients with refractory/ relapsed AML were enrolled in this study, and the doseescalation section allowed definition of a recommended dose of ORY1001 for the expanded phase, of $140 \mu \mathrm{g} / \mathrm{m}^{2} /$ day. ${ }^{102}$ At this dose, the drug was relatively well tolerated, and the most frequent adverse events were asthenia, febrile neutropenia, constipation, and peripheral edema. ${ }^{102}$ Importantly, ORY1001 was evaluated in an extension cohort of 14 AML patients with relapsing AML subtypes predicted to be more sensitive according to preclinical studies (ie, ten AML MLL/ translocated and four acute erythroleukemia/M6). Objective responses were seen in 36\% and blast-cell differentiation in blood observed in $64 \%$ of these patients. ${ }^{102}$ These observations further support additional studies exploring the antileukemic effects of ORY1001.

After the end of this Phase I study in AML, further development of ORY1001 will be carried out by Roche (Basel, Switzerland) and the compound name will be RG6016. RG6016 will be additionally evaluated in AML patients and in small-cell lung cancer patients in the context of a Phase I study (NCT02913443). Another LSD1 inhibitor, ORY2001, generated by Oryzon is under evaluation in a Phase I clinical study in neurodegenerative disease (Alzheimer's disease, Parkinson's disease, and Huntington's disease). This study was preceded by one initiated in early 2016 to determine the safety, tolerability, and kinetics of ORY2001 in healthy volunteers.

Other $N$-alkylated compounds, RN1 and RN7, are currently being evaluated in preclinical models. Both those compounds displayed a selective and potent LSD1 inhibitory capacity $\left(\mathrm{IC}_{50} 10-30 \mathrm{nM}\right)$; an important property of these compounds is in their brain penetration capacity, eliciting inhibitory effects on long-term, but not short-term memory formation. ${ }^{103} \mathrm{RN} 1$ was evaluated in preclinical models for its capacity to act as an agent stimulating fetal hemoglobin synthesis in adult erythroid cells and for its antileukemic properties. Concerning the first point, RN1 was evaluated in a mouse model of sickle-cell disease, showing that drug administration induced fetal hemoglobin synthesis in erythroid cells, reduced disease pathology, ${ }^{104}$ and reduced oxidative-induced damage to erythroid cells. ${ }^{105}$ Preclinical studies in baboons support the efficacy (evaluated by fetal hemoglobin increase) and safety of long-term administration of RN1 in baboons. ${ }^{106,107}$ These observations support further development of the LSD1 inhibitor RN1 in the treatment of sickle-cell disease. ${ }^{106,107}$

Other studies on RN1 were focused on evaluating the antileukemic effects of this inhibitor. Studies performed on leukemic cell lines showed that leukemic cells with MLL translocations or bearing RUNX1-RUNX1T1 (AML1-ETO) translocations are particularly sensitive to cell death, cell differentiation, and inhibition of cell proliferation in vitro and in vivo induced by RN1. ${ }^{106}$ The in vitro assay indicated that $\mathrm{RN} 1$ is a potent $\mathrm{LSD} 1$ inhibitor with an $\mathrm{IC}_{50}$ assayed on inhibition of cell proliferation corresponding to $1-5 \mathrm{nM} .{ }^{108}$ These observations suggest that both MLL-rearranged and RUNX1rearranged AML may converge on similar downstream oncogenic pathways that are impacted by LSD1 inhibition. ${ }^{108}$

In 2015, the Cancer Epigenetic Department of GlaxoSmithKline (Philadelphia, PA, USA) performed a screening on a library of 2.5 million compounds, and discovered a series of small molecules with LSD1-inhibitory activity that led to the development of three potent LSD1 inhibitors: GSK2879552, GSKLSD1 and GSK2699537. All three molecules are $N$-alkylated cyclopropylamine derivatives and act as potent irreversible LSD1 inhibitors. The pharmacokinetic and pharmacodynamic properties of GSK2879552 indicated that this compound was suitable for clinical development. GSK2879552 treatment of a large panel of tumor cell lines indicated that AML and small-cell lung cancer cells were uniquely sensitive. ${ }^{109}$ The antitumor effect against small-cell lung cancer was characterized in detail, providing evidence that the sensitivity of these tumor cells to GSK2879552 correlated with DNA hypomethylation of a signature set of probes. ${ }^{109}$ GSK2879552 is under investigation in the context of a Phase I study in a subset of cancer patients with relapsed/ refractory small-cell lung cancer (NCT02034123) (Table 1).

Incyte (Palo Alto, CA, USA) recently developed a new LSD1 inhibitor, INCB059872, displaying properties suitable for clinical development. This inhibitor was potent and selective for LSD1 and was orally bioavailable. Initial pharmacodynamic studies confirmed the capacity of this inhibitor, like other LSD1 inhibitors, to induce apoptosis and differentiation of leukemic cells displaying MLL rearrangements. ${ }^{108}$ Studies in xenograft mice transplanted with human MLLAF9 leukemic cells showed prolonged in vivo effects of INCB059872, allowing its administration with an alternateday regimen. ${ }^{110}$ Preclinical studies with INCB059872 showed a synergistic interaction with ATRA ${ }^{111}$ and with a BET inhibitor $^{112}$ in inducing cell differentiation and inhibiting 
the growth of non-APL AML cells. In another set of studies, preliminary evidence was provided on possible synergy between INCB059872 and various signal-transduction inhibitors (such as PIM-kinase inhibitors, JAK1/2 inhibitors, or $\mathrm{PI} 3 \mathrm{~K} \delta$-selective inhibitor) in some AML models. ${ }^{113}$ Other studies were focused on exploring the possible antitumor effects of INCB059872 in some solid tumors. Interestingly, preclinical studies showed significant antitumor effects of this LSD1 inhibitor alone or in combination with chemotherapy in Ewing sarcoma cell lines. ${ }^{113}$ In vivo studies in mice xenografted with human Ewing sarcoma cell lines confirmed their sensitivity to the antitumor effects of INCB059872. ${ }^{114}$ Interestingly, using patient-derived xenograft models, evidence was provided that tumors with EWS-FLI translocations were particularly inhibited in their growth by the LSD1 inhibitor. ${ }^{115}$ Finally, other preclinical studies confirmed the observations made with ORY1001 and showed clear sensitivity of smallcell lung cancer to LSD1 inhibitors. ${ }^{116}$ On the basis of these observations, Incyte has launched two clinical trials based on the administration of INCB059872: a Phase I/II study of dose escalation/dose expansion in patients with advanced cancer (NCT02712905), and a Phase I dose-escalation study in sickle-cell disease (NCT03132324) (Table 1).

Recently, new LSD1 inhibitors pertaining to this chemical subtype have been reported. These compounds are promising for their potency, specificity, and pharmacologic properties. Takeda (Osaka, Japan) reported a new LSD1 inhibitor, T3775440, a tranylcypromine derivate characterized by high LSD1-inhibitory activity ( $\left.\mathrm{EC}_{50} 2 \mathrm{nM}\right)$. A screening of the effects of this compound against a large panel of leukemic cell lines showed a sensitivity of erythroid and megakaryocytic leukemic cell lines. The growth-inhibitory effect observed on these cells seems to be related to a transdifferentiating effect consisting of the induction of monocyte differentiation. ${ }^{117}$ In vivo experiments in normal mice showed that T3775440, as well as other LSD1 inhibitors, exerted an inhibitory effect on erythroid and megakaryocytic progenitors, resulting in thrombocytopenia. ${ }^{117}$ This inhibitor effect on erythromegakaryopoiesis could be related to the capacity of T3775440 to disrupt Gfilb-containing transcriptional complexes. ${ }^{111}$ These observations support the hypothesis that LSD1 inhibitors could be evaluated for the treatment of M6 and M7 AML. In line with this observation, as mentioned, M6 AML patients were shown to be frequent responders to treatment with the ORY1001 LSD1 inhibitor. ${ }^{102}$

Ogasawara et al developed novel LSD1 inhibitors, NCD25 and NCD38, which consist of two moieties: a tranylcyprominebased moiety with LSD1-inhibiting activity and a lysine that is designed to recognize, with high affinity, an LSD1 enzymatic pocket, thus allowing selective inhibitory activity restricted to LSD1 and not extended to other MAO enzymes. ${ }^{118}$ These two LSD1 inhibitors were recently characterized for their anticancer properties. Sugino et al explored the antileukemic activity of NCD25 and NCD38. ${ }^{119}$ NCD25 and NCD38 inhibited LSD1 with $\mathrm{EC}_{50}$ of about $500 \mathrm{nM}$. Through the study of a panel of sensitive leukemic cell lines and gene-expression studies in LSD1 inhibitor-treated cells, the conclusion was reached that these inhibitors derepress superenhancers of hematopoietic regulators (such as Gfil, ERG, and CEBPA) that are abnormally silenced by LSD1 and via this mechanism inhibit leukemic programs and promote cell differentiation. ${ }^{119}$ Furthermore, NCD38 showed a marked inhibitory effect on colony formation by primary leukemic cells derived from MLL-rearranged AML, erythroleukemia, and MDS. ${ }^{119}$ These findings provide a rationale for clinical trials of LSD1 inhibitors in MDSs. ${ }^{119}$ Interestingly, NCD38 and NCL1, another lysine-specific LSD1 inhibitor, ${ }^{120}$ were shown to inhibit glioma SCs. ${ }^{121}$

The use of noncovalent reversible LSD1 inhibitors could provide some advantages compared to irreversible inhibitors, particularly as regards a safer metabolic profile. Only a limited number of noncovalent LSD1 inhibitors have been developed, and some are promising in preclinical assay in terms of development of antileukemic drugs. ${ }^{122}$ Several compounds with these properties and submicromolar potency have been developed. Among these compounds, particularly interesting is the inhibitor SP2509, containing a benzohydrazide scaffold, and with a $\mathrm{K}_{\mathrm{i}}$ on LSD1 activity of about $30 \mathrm{nM} .^{123}$

The effect of SP2509 on leukemic cell lines was tested, providing evidence about effects comparable to those induced by irreversible LSD1 inhibitors (ie, inhibition of proliferation, induction of apoptosis and cell differentiation). ${ }^{124}$ This compound was tested also on primary AML cells, providing evidence that NPM1 and MLL-rearranged leukemic cells are particularly sensitive to the effects of SP2509. ${ }^{124}$ Interestingly, cotreatment with an HDAC inhibitor (panobinostat) and SP2509 was synergistically inhibitory for AML blasts. ${ }^{124}$

Another reversible LSD1 inhibitor, JL1037, was recently identified through computer-aided drug-design technology. ${ }^{125}$ This compound displayed a reversible and selective LSD1inhibitory activity with $\mathrm{IC}_{50}$ of $100 \mathrm{nM}$ and antileukemic effects like those observed using other LSD1 inhibitors. ${ }^{125}$ Exploration of the inhibitory activity of JL1037 on leukemic cells revealed induction of apoptotic and autophagic responses. ${ }^{125}$

From high-throughput screening, a new series of compounds was identified, named $4 H$-thieno[3,2- $b]$ pyrrole5-carboxamide, with inhibitory activity against LSD1. ${ }^{126}$ 
Structure-guided optimization of this chemical series led to the isolation of some compounds $(46,49$, and 50) displaying selective inhibitory activity for LSD1 and pharmacological effects comparable to those observed for other LSD1 inhibitors. ${ }^{126}$

A high throughput scree and subsequent in silico screening led to the development of (4-cyanophenyl) glycine derivatives as potent reversible LSD1 inhibitors. ${ }^{127}$ The scaffold-hopping method was used to develop structurally new LSD1 inhibitors: a series of 4-(pyrrolidin-3-yl) benzonitrile derivatives that act as compounds mimicking the GSK690 LSD1 inhibitor, with improved selectivity over the HERG ion channel and no activity against related MOA enzymes. ${ }^{128}$ Among these inhibitors, particularly promising is the compound $21 \mathrm{G} .{ }^{128}$

Recently, the development of tranylcypromine derivatives targeting both LSD1 and HDAC was reported. ${ }^{129}$ Particularly, compound 7 displayed potent inhibitory activity against HDAC1 and HDAC2, with $\mathrm{IC}_{50}$ of $15 \mathrm{nM}$ and $13 \mathrm{nM}$, respectively, as well as potent inhibition against LSD1, with $\mathrm{IC}_{50}$ of $1.20 \mu \mathrm{M} .{ }^{123}$ At the biochemical level, this compound increased cellular $\mathrm{H} 3 \mathrm{~K} 4$ and $\mathrm{H} 3 \mathrm{~K} 9$ methylation, as well as acetylation. $^{129}$

\section{DOTIL}

\section{Structure and function}

One of the most important and studied histone-modification pathways is represented by lysine methylation, occurring as mono-, di-, or tri methylation. The biologic consequences of histone-lysine methylation are variable in that they can result in both repression or derepression of gene expression.
There are two distinct classes of histone-lysine KMTs: a first class of proteins is characterized by the presence in its sequence of an evolutionary conserved SET catalytic methyltransferase domain; a second class lacks an SET domain and is represented by a single member - DOT1/DOT1L.

DOT1 was originally identified in yeast as a gene that disrupts telomeric silencing when overexpressed. In mammalians, this protein is called DOT1L. DOT1L is the only known KMT able to methylate $\mathrm{H} 3 \mathrm{~K} 79$ : this methylation is associated with active transcription and occurs on the nucleosome core, not on the histone tail. ${ }^{130}$ No demethylase has been identified to remove H3K79 methylation, thus indicating that DOT1L is the key determinant for $\mathrm{H} 3 \mathrm{~K} 79$ methylation. In addition to its role in DNA methylation, DOT1L is also involved in DNA-repair mechanisms and cell-cycle regulation. ${ }^{124}$ DOT1L is a unique enzyme in the KMT superfamily for its structure. Although DOT1L is a lysine methyltransferase, sequence characteristics indicate similarity to the arginine methyltransferase family. ${ }^{131}$

The three-dimensional structure of DOT1L reveals an elongated molecule with two domains different from those observed in SET-containing proteins and like those observed in non-SET domain-containing methyltransferases; ${ }^{132}$ the SAM-binding site of DOT1L presented at the level of the C-terminal $\alpha / \beta$ domain (Figure 2). ${ }^{132}$ The DOT1L protein is a dynamic enzyme able to have different conformational states: particularly, following SAM binding, the protein displays a more closed conformation. ${ }^{132}$ Study of the protein conformation, when DOT1L binds various types of competitive SAM inhibitors, indicates that loops in SAM binding and near this binding site adopt different conformations. Though not

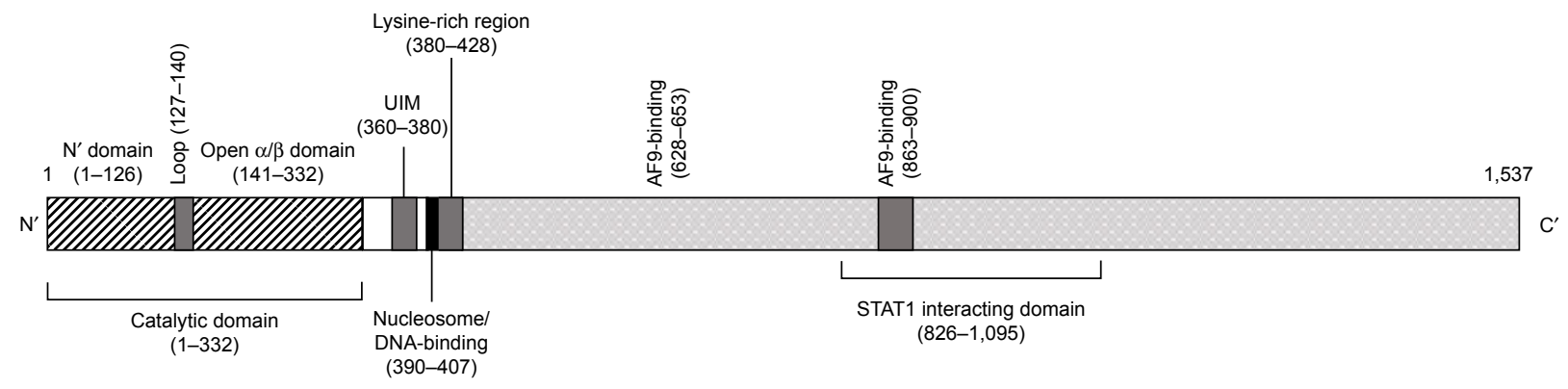

Figure 2 Schematic representation of the DOTIL protein.

Notes: Some physiologically relevant domains are indicated. A large catalytic region (I-332) contains three domains: $\mathrm{N}^{\prime}(\mathrm{I}-126)$, loop (I27-I40), and an open $\alpha / \beta$ domain. The $N$-terminal domain consist of five $\alpha$-helices and two $\beta$-strand hairpins. Loop I27-I40 is a protein-flexible loop. The open $\alpha / \beta$ domain (amino-acid residues I4I-332) contains a seven-strand central $\beta$-sheet and five $\alpha$-helices. Part of the flexible loop region and the open $\alpha / \beta$ domain contributes to the formation of an $S$-adenosyl-Lmethionine (SAM)-binding pocket. A ubiquitin-interaction motif (UIM) is located at amino-acid residues 360-380 and involved in ubiquitin H2B and DOTIL-Bat 3 interactions, both required to facilitate efficient $\mathrm{H} 3 \mathrm{~K} 79$ dimethylation and trimethylation. A lysine-rich region (380-428) is required for nucleosome binding and interacts with the ubiquitin $\mathrm{H} 2 \mathrm{~B}$ : deletion of this region resulted in reduced demethylation and trimethylation. Within the lysine-rich region, there is a nucleosome/DNA-binding motif (390-407). Two AF9-binding regions have been mapped: the 628-653 binding region contains one binding site for AF9; the 863-900 binding region contains two AF9-binding sites. The DOTIL $_{865-874}$-binding domain is strictly required for the binding of the AF9-ENL complex through the C-terminal region of ENL. The 580-I,I83 region contains an STTIbinding site. 
mutated, DOT1L plays and important role in leukemogenesis. In fact, MLL fusion proteins interact directly or indirectly with DOT1L and result in inappropriate recruitment of this KMT at the level of the gene targets of MLL fusion proteins, such as HOXA and MEIS1, resulting in their transcriptional activation. ${ }^{133,134}$

Recent studies have in part clarified the mechanism through which DOT1L modulates transcriptional activity and contributes to the deregulated gene expression observed in MLL-rearranged leukemias. The capacity of DOT1L to interact with other proteins to form multiprotein complexes is fundamental for its physiological function of transcriptional regulator and for its relevant contribution to the pathogenesis of MLL-rearranged leukemias. DOT1L has been found to be involved in the formation of complexes with an ENL family protein and an AF10 family protein, such as AF10 or AF9. The association of DOT1L with these proteins increases the methyltransferase activity of DOT1L to produce highly methylated H3K79 me2/3 markers. ${ }^{135}$

Many of these proteins complexing with DOT1L are also partners of MLL in the formation of MLL-fusion proteins. In MLL-rearranged leukemias, these partners interact with DOT1L, and through this interaction drive the DOT1L complex at the level of MLL-fusion target genes, such as HOXA and MEIS1, thus inducing their high H3K79 methylation and consequently their high expression. This is the basic mechanism through which DOT1L contributes in a relevant way to MLL-fusion leukemia, enabling a high expression of MLL target genes. The AF9 and AF10 proteins act as readers of histone modifications. ${ }^{136,137}$

AF9 interacts with DOT1L, forming a stable complex with its C-terminus (Figure 2). AF9 interacts with H3K9ac, which is enriched in transcriptionally active genes. ${ }^{126}$ Most AF9-bound genes are enriched for both H3K9 ac and H3K79 me3. ${ }^{137}$ Importantly, AF9 knockdown leads to decreased H3K79 methylation on target genes. ${ }^{137}$ AF10 determines higher H3K79 methylation states, and thus enhances the methyltransferase activity of DOT1L. ${ }^{135}$ AF10 interacts with unmodified $\mathrm{H} 3 \mathrm{~K} 27$, but not methylated $\mathrm{H} 3 \mathrm{~K} 27$, thus explaining why H3K27 methylation does not often co-occur with $\mathrm{H} 3 \mathrm{~K} 79$ methylation on the genetic region. ${ }^{136}$

Another important element in the understanding of the mechanism through which DOT1L exerts its leukemogenic function derives from a recent study showing that DOT1L prevents SIRT1-mediated gene silencing at the level of gene regions recognized by MLL-fusion proteins. Particularly, DOT1L recruited at the level of MLL-fusion target loci prevents SIRT1 from deacetylating H3K9. ${ }^{138}$
When DOT1L is inactivated by chemical inhibitors, SIRT1 reacquires the capacity to bind to these genetic loci and promotes deacetylation of $\mathrm{H} 3 \mathrm{~K}$, which leads to $\mathrm{H} 3 \mathrm{~K} 9$ methylation and consequent downregulation of MLL-fusion target-gene expression. ${ }^{138}$ Finally, SIRT1 activators synergize with DOT1L inhibitors and accelerate downregulation of MLL-fusion target genes. ${ }^{138}$ The mechanisms through which DOT1L contributes to MLL-driven leukemogenesis are very complex, and this is in large part related to the capacity of MLL-fusion proteins to form large complexes interacting with numerous other nuclear proteins. More than 70 genes have been shown to fuse with MLL. In most cases, MLL is fused with a component of the AF4-ENL-P-TEFb (AEP) complex or the DOT1L-AF10-ENL complex. These complexes involve a member of the ENL family, such as ENL and AF9. The ENL proteins contain a YEATS domain, recognizing H3K9/18/27 Ac. The AEP complex contains AF4 protein families, which provide various interaction platforms for cofactors involved in initiation and elongation of transcription. The mechanism through which the MLL-AF10-ENL complex transforms HSCs operates through the DOT1L-interaction domain, ${ }^{133}$ while the MLL-ENL-AF9 involves the ANCI-homology domain, which interacts with both DOT1L and AF4. ${ }^{139}$

A recent study provided evidence that MLL-F10-DOT1L acts through a more complex mechanism that does not need the simple recruitment of DOT1L to the target promoters, but involves also the capacity of DOT1L through its ENLbinding motifs to recruit AF4. ${ }^{132}$ According to these observations, it was suggested that the simultaneous inhibition of the MLL fusion-AF4 complex and DOT1L may provide more effective treatment of MLL-rearranged leukemia. ${ }^{140}$

Interestingly, recent studies have shown that DOT1L may represent a therapeutic target for the treatment of DNMT3Amutant AML. DNMT3A is mutated in about $20 \%$ of AML and usually associated with a negative prognosis. In $60 \%$ of cases, DNMT3A mutations involve the arginine at aminoacid position 882 and determine a marked loss of cellular DNA methyltransferase activity. Ablation of DNMT3A in HSCs determines a pronounced expansion of HSCs and a progressive block in cell differentiation. HSCs deficient in DNMT3A overexpress DOT1L and have increased H3K79 methylation, particularly at the level of DNA regions corresponding to genes highly dysregulated in leukemia. ${ }^{135}$ These observations have suggested that DOT1L could represent a target in DNMT3A-mutated AML. In line with this hypothesis, DOT1L inhibitors blocked the growth of DNMT3Amutated cell lines and primary AML cells and induced cell differentiation. ${ }^{141}$ 


\section{DOTIL and hematopoiesis}

Gene-knockout studies in mice have supported a role for DOT1L in the control of normal hematopoiesis. DOT1L $\mathrm{L}^{-/}$ mice developed more slowly and died on embryonic days 10.5-13.5, exhibiting pronounced anemia. ${ }^{140}$ Analysis of the hematopoietic tissue of DOT1L-deficient mice displayed a selective defect at the level of erythroid but not myeloid progenitors: erythroid progenitors failed to develop normally, displayed delayed progression through the cell cycle, accumulated in $\mathrm{G}_{0} / \mathrm{G}_{1}$, and exhibited a great tendency toward apoptosis, even in the presence of erythroid growth factors. ${ }^{142}$ GATA2 expression was greatly decreased in erythroid cells of DOT1L-deficient mice, while PU1 levels were increased. ${ }^{142}$

Subsequently, two additional studies demonstrated that DOT1L plays an important role in maintaining normal adult hematopoiesis, using conditional DOT1L-knockout mice, coupled with serial bone-transplant assays. ${ }^{140,141}$ Knockout of DOT1L in bone marrow causes pancytopenia and depletes HSCs and various progenitor cell (PC) populations, thus indicating an essential role for DOT1L in maintaining HSCs and HPCs. ${ }^{143,144}$

Daigle et al explored the effect of a potent DOT1L inhibitor (EPZ004777) on in vivo murine hematopoiesis, showing that the administration of this inhibitor at tolerable pharmacodynamically active doses elicited only slight effects consisting of a moderate and unexplained increase of neutrophils, monocytes, and lymphocytes not accompanied by any significant change at the level of frequency of bone-marrow colony-forming cells. HSCs and granulomonocytic progenitors were not affected by the drug. ${ }^{145}$ Differences observed in knockout vs drug-inhibition studies are seemingly related to differences in DOT1L silencing achieved by these different procedures.

\section{DOTIL inhibitors}

Given the important role of DOT1L in MLL-rearranged leukemia, many recent studies have investigated the development and characterization of DOT1L inhibitors and explored their potential role in leukemia therapy (Table 2). Three compounds were initially reported - EPZ004777, EPZ5676, and SGC0946 - and selected for their specific inhibitory activity against DOT1L. ${ }^{145-147}$

All these three compounds act as competitive inhibitors of SAM, the cofactor required for the methyltransferase activity of DOT1L. More recently, new DOT1L inhibitors have been identified. Wang et al reported the identification of a new class of DOT1L inhibitors, characterized by a scaffold of $[1,2,4]$-triazolo-[3,4- $b][1,3,4]$-thiadiazole. The most active of these compounds, compound 6 is a selective DOT1L inhibitor with on $\mathrm{IC}_{50}$ of $8.3 \mu \mathrm{M} .{ }^{148}$

The DOT1L inhibitor EPZ004777 is characterized by a considerable inhibitory potency $\left(\mathrm{IC}_{50} 400 \mathrm{pM}\right)$. This inhibitor was designed to mimic the SAM enzyme cofactor. EPZ was competitive with SAM and not with the peptide substrate. EPZ represents the standard DOT1L inhibitors with several typical pharmacological effects, consisting of global reduction of H3K 79 me2 levels, inhibition of the expression of HOXA9 and MEIS1, and inhibition of the growth in vitro and in vivo of MLL-rearranged leukemic cells. ${ }^{145}$ Taking advantage of the crystal structure of the DOT1L-EPZ004777 complex, SG0946 inhibitors with increased in vitro and in vivo cellular potencies were developed. ${ }^{145}$ SG0946 contains a bromo-substitution at position 7 compared to EPZ004777 and was more potent in chemical and cellular assays. ${ }^{147}$ A major advancement in the field was represented by the discovery of the EPZ5676 DOT1L inhibitor by Daigle et al in 2013. ${ }^{146}$ This inhibitor binds the DOT1L enzyme at the level of the cofactor-binding site with an affinity of $0.03 \mathrm{nM}$ and reduces H3K79 me2 levels in MV411 cells with an $\mathrm{IC}_{50}$ of $3 \mathrm{nM} .{ }^{147}$ Preclinical studies have shown that the continuous infusion of EPZ5676 was able to induce complete tumor regression in immunocompromised mice xenografted with MLL-rearranged MV411 cells. ${ }^{146}$ The efficacy of EPZ5676 in preclinical models has triggered the clinical development of this inhibitor as an anticancer drug. In clinical studies, the inhibitor is administered by continuous intravenous infusion. Alternatively, EPZ5676 can be administered by subcutaneous bolus formulation, but this mode of administration has been used only in preclinical studies. ${ }^{149}$ Interestingly, in MLL-rearranged AML cells, EPZ5676 synergizes with standard antileukemic drugs and the hypomethylating agent azacitidine, eg, AraC and daunorubicin, to inhibit the growth of leukemic cells. ${ }^{150}$

The metabolism and disposition of EPZ5676 has been explored in preclinical animals (rats and dogs) and humans, showing that fecal excretion of the intact drug and its metabolites is responsible for the majority of drug-related elimination, with low renal excretion. ${ }^{151}$ Despite the pharmacokinetic improvements in EPZ5676 compared to other LSD1 inhibitors, this compound still shows low oral bioavailability.

A first Phase I study (completed) was designed to evaluate safety profile, pharmacokinetics, and pharmacodynamics and obtain preliminary indications on clinical activity in adult patients with relapsed/refractory acute leukemia (either myeloid or lymphoid) (Table 2). ${ }^{152}$ A total of 49 patients were treated (either in the dose-escalation or expansion phase), and six patients displayed objective response, including 
Table 2 Main properties of DOTIL inhibitors

\begin{tabular}{|c|c|c|c|c|c|}
\hline Name & Clinical structure & $\begin{array}{l}\text { Potency of } \\
\text { inhibitor activities }\end{array}$ & Major biological effects & $\begin{array}{l}\text { Preclinical and clinical } \\
\text { studies }\end{array}$ & References \\
\hline EPZ004777 & $\begin{array}{l}\text { Aminonucleoside, } \\
\text { SAM-competitive }\end{array}$ & $\begin{array}{l}\text { DOTIL } \mathrm{K}_{\mathrm{i}} 0.5 \mathrm{nM} \\
\text { MV4II proliferation, } \\
\mathrm{IC}_{50} \mathrm{I} 5 \mathrm{I} \mathrm{nM} \\
\mathrm{H} 3 \mathrm{~K} 79 \mathrm{IC}_{50} 84 \mathrm{nM}\end{array}$ & $\begin{array}{l}\text { Inhibition of cellular H3K79 } \\
\text { methylation; inhibition of } \\
\text { proliferation of MLL-rearranged } \\
\text { leukemia cells; inhibition } \\
\text { of HOXA and MEISI gene } \\
\text { expression }\end{array}$ & $\begin{array}{l}\text { Poor pharmacokinetic } \\
\text { properties }\end{array}$ & $\begin{array}{l}\text { Daigle } \\
\text { et al }\left.\right|^{145}\end{array}$ \\
\hline EPZ-5676 & $\begin{array}{l}\text { Aminonucleoside } \\
\text { SAM-competitive }\end{array}$ & $\begin{array}{l}\text { DOTIL K } 0.08 \mathrm{nM} \\
\text { MV4II proliferation, } \\
\mathrm{IC}_{50} 3-15 \mathrm{nM} \\
\mathrm{H} 3 \mathrm{~K} 79 \mathrm{IC}_{50} 3-7 \mathrm{nM}\end{array}$ & $\begin{array}{l}\text { Inhibition of cellular H3K79 } \\
\text { methylation; inhibition of } \\
\text { proliferation of MLL-rearranged } \\
\text { leukemia cells in vitro and } \\
\text { in vivo; inhibition of HOXA and } \\
\text { MEISI gene expression }\end{array}$ & $\begin{array}{l}\text { In vivo pharmacokinetics } \\
\text { showed moderate-high } \\
\text { clearance and low } \\
\text { oral bioavailability; } \\
\text { drug administered by } \\
\text { continuous intravenous } \\
\text { infusion in phase I clinical } \\
\text { trials }\end{array}$ & $\begin{array}{l}\text { Daigle } \\
\text { et al }{ }^{146}\end{array}$ \\
\hline SGC0946 & $\begin{array}{l}\text { Aminonucleoside (brominated } \\
\text { analog of EPZ2004777), } \\
\text { SAM-competitive }\end{array}$ & $\begin{array}{l}\text { DOTIL K } 0.3 \mathrm{nM} \\
\text { H3K79ma2 IC } 80 \mathrm{nM}\end{array}$ & $\begin{array}{l}\text { Decrease of viability of } \\
\text { MLL-AF9-transformed cells }\end{array}$ & & Yu et al ${ }^{147}$ \\
\hline CN-SAH & 5-Adenosyl-L-homocysteine & DOTIL $K_{\mathrm{i}} 13 \mathrm{nM}$ & Inhibition of DOTIL activity & None & Spurr et a $\left.\right|^{191}$ \\
\hline $\begin{array}{l}\text { Compound } 12 \\
\text { and } 13\end{array}$ & $\begin{array}{l}\text { SAM-competitive, but it does } \\
\text { not bind to the SAM site, but } \\
\text { to a site near to the SAM site }\end{array}$ & $\begin{array}{l}\text { DOTIL K } 0.4-I .4 \mathrm{nM} \\
\text { MV4II proliferation, } \\
\mathrm{IC}_{50} 85-\mathrm{I} 28 \mathrm{nM} \\
\mathrm{H} 3 \mathrm{~K} 79 \mathrm{IC}_{50} \mathrm{I} \text { - } 23 \mathrm{nM}\end{array}$ & $\begin{array}{l}\text { Inhibition of cellular H3K79 } \\
\text { methylation; inhibition of } \\
\text { proliferation of MLL-rearranged } \\
\text { leukemia cells; inhibition of } \\
\text { HOXA gene expression }\end{array}$ & $\begin{array}{l}\text { Good oral bioavailability; } \\
\text { high blood clearance, high } \\
\text { volume of distribution, } \\
\text { moderate half-life }\end{array}$ & Chen et al ${ }^{192}$ \\
\hline Compound 7 & $\begin{array}{l}\text { Structure not nucleoside- } \\
\text { related }\end{array}$ & $\begin{array}{l}\text { DOTIL } \mathrm{K}_{\mathrm{i}}<0 . \mathrm{I} \mathrm{nM} \\
\text { MV4-II proliferation, } \\
\mathrm{IC}_{50} 5 \mathrm{nM} \\
\mathrm{H} 3 \mathrm{~K} 79 \mathrm{IC}_{50} 3 \mathrm{nM}\end{array}$ & $\begin{array}{l}\text { Inhibition of cellular H3K79 } \\
\text { methylation; inhibition of } \\
\text { proliferation of MLL-rearranged } \\
\text { leukemia cells in vitro; inhibition } \\
\text { of HOXA gene expression; } \\
\text { more potent than EPZ } 5676 \text { in } \\
\text { comparative assays }\end{array}$ & None & $\begin{array}{l}\text { Möbitz } \\
\text { et al }{ }^{193}\end{array}$ \\
\hline Compound 6 & $\begin{array}{l}\text { Scaffold of }[1,2,4] \text {-triazolo- } \\
{[3,4-b][1,3,4] \text { thiadiazole }}\end{array}$ & $\begin{array}{l}\text { DOTIL K } 8 \mathrm{nM} \\
\text { MV4II proliferation, } \\
22 \mathrm{mM} \\
\mathrm{H} 3 \mathrm{~K} 79 \mathrm{IC}_{50}, 10 \mathrm{nM}\end{array}$ & $\begin{array}{l}\text { Inhibition of proliferation of } \\
\text { MLL-rearranged leukemia cells } \\
\text { in vitro }\end{array}$ & None & $\begin{array}{l}\text { Wang } \\
\text { et al }{ }^{148}\end{array}$ \\
\hline
\end{tabular}

Abbreviations: SAM, S-adenosyl-L-methionine; MLL, mixed-lineage leukemia.

one morphologic complete remission, one cytogenetic complete response, one partial response, and three resolutions of leukemia cutis. ${ }^{152}$ Drug administration is usually well tolerated, and about $15 \%$ of treated patients display adverse events. ${ }^{152}$ In another Phase I study, pinometostat was evaluated in a cohort of pediatric patients with relapsed or refractory MLLrearranged acute leukemia. ${ }^{147}$ No objective responses were observed in these patients, and only transient reductions in blast-cell counts were observed in $40 \%$ of treated patients. ${ }^{153}$

\section{Menin}

\section{Menin structure and function}

Menin is a $67 \mathrm{kDa}$ protein encoded by the MEN1 gene localized on chromosome 11q13. ${ }^{154}$ Menin is a nuclear protein, ubiquitously expressed. ${ }^{155}$ Menin interacts directly with the N-terminal region of MLL; ${ }^{156-158}$ this N-terminal MLL region is retained in all MLL-fusion proteins and plays a key role in the binding of MLL and MLL-fusion proteins to target genes, such as $\operatorname{HOXA9.} .^{156,157,159,160}$ The capacity of MLL-fusion proteins to bind menin is strictly required for their leukemogenic activity: in fact, mutations at the level of the N-terminal region of MLL-fusion proteins block their capacity to induce leukemia and to upregulate HOXA gene expression. ${ }^{154}$ These observations have indicated that the menin-MLL interaction represents a potentially important target in the treatment of MLL-rearranged AML. Analysis of the structure of the menin protein is essential for a better understanding of its function. Human menin is composed of 615 amino acids and it is a globular protein. The linear structure of the protein shows four structured regions that form the structured core and represent regions conserved during evolution, interspaced by three loop regions. In contrast to the 
structured regions, the loop regions and C-terminal region are variable among species and contain sites of posttranslational modification of the protein, such as phosphorylation and SUMOylation (Figure 3). ${ }^{161}$ Structural studies have shown that menin is an $\alpha$-helical protein with three folds based on three tetratricopeptide repeats: ${ }^{162}$ these repeats form a large central cavity that represents the binding site for the proteinprotein interactions with MLL and JunD8127. This central cavity is a relatively rigid structure that does not change conformation upon binding of protein ligand.

As stated, an essential function of menin is dependent upon its capacity to interact with the N-terminal region of MLL: at the level of this region of the MLL molecule, two menin-binding motifs have been discovered: highaffinity MBM1, encompassing residues 6-13, and lowaffinity MBM2, encompassing residues 24-40 (Figure 3). ${ }^{158}$ The MBM1 pocket on menin represents a major site for targeting by small-molecule inhibitors.

Menin acts as an oncogenic cofactor of MLL-fusion proteins in leukemia. This function is related to the capacity of menin to interact with the N-terminus of MLL, an MLL region retained in all MLL-fusion proteins. Through this mechanism, menin drives MLL and MLL-fusion proteins to target genes. ${ }^{156,157,159,160}$ The essential role of menin in supporting the oncogenic activity of MLL-fusion proteins is directly shown by the observation that loss of menin binding by MLL-fusion proteins abolishes their capacity to upregulate $H O X$ gene expression and to induce leukemia in vivo in mice. ${ }^{161}$ Furthermore, expression of a dominant-negative inhibitor composed of an amino-terminal MLL sequence acts as a blocking agent of the oncogenic potential of MLL-fusion proteins. ${ }^{162}$ Finally, small-molecule inhibitors able to bind to menin and disrupt the binding of these molecules to MLL inhibit the proliferation of MLL-fusion-bearing leukemic cells and induce their differentiation. ${ }^{163}$
The requirement of menin for leukemogenic activity of MLL-fusion proteins is strongly supported by various experimental studies, and represents a strong rationale to develop small-molecule inhibitors to target the menin-MLL interactions. The analysis of a large set of different MLL-fusion proteins clearly supported the capacity of a potent menin inhibitor, MI2-2, to induce growth arrest, differentiation, and downregulation of MLL-fusion target genes in leukemia cells transformed with various MLL fusions. ${ }^{164}$

Importantly, this menin inhibitor elicited its inhibitory activity on AML cells displaying different types of MLL-fusion genes. As mentioned, MLL-rearranged AML is sensitive to DOT1L inhibitors. However, DOT1L inhibitors act slowly on these leukemia cells, and their effect on many MLL-rearranged cell lines is limited. To bypass this important limitation, it was discovered that a combined inhibition of both DOT1L and menin resulted in strong, complementary inhibition of MLLrearranged leukemic cells, as supported by induction of cell killing and differentiation. ${ }^{165}$ At the gene-expression level, the combination of the two drugs elicited a more marked inhibitory effect on MLL-fusion and MYC target genes. ${ }^{165}$

Analysis of $H O X A$ and $H O X B$ cluster-gene expression in AML allows identification of four AML subgroups:

1. a subgroup not expressing $\mathrm{HOXA}$ or $\mathrm{HOXB}$, represented by AML, characterized by PML-RAR $\alpha$ and AML1-ETO fusion transcripts

2. a subgroup expressing only HOXA, represented by AML, characterized by MLL-fusion genes and by frequent complex karyotypes

3. a subgroup expressing only $\mathrm{HOXB}$, represented by AML, frequently characterized by CBFB-MYH11 rearrangements

4. a subgroup expressing both HOXA and HOXB, represented by AML, frequently characterized by NPM1 mutations in most cases and more rarely by MLL-PTD. ${ }^{166}$

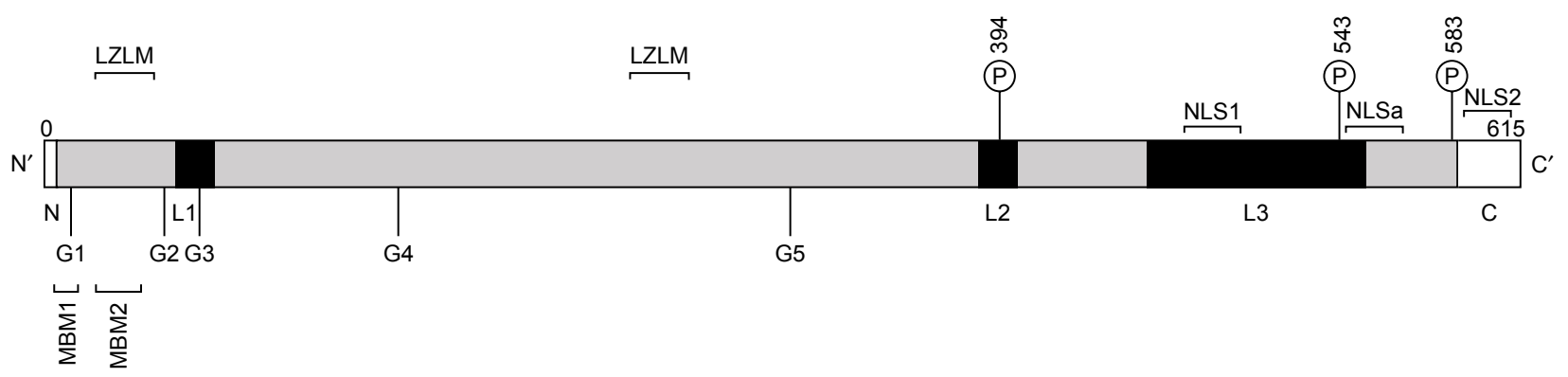

Figure 3 Linear structure of human menin.

Notes: Schematics of a sequence of human menin composed of 615 amino acids. Elements of the folded core of the protein are in gray. These elements contribute to the formation of a central cavity. Three loops, LI-L3, are shown in black. Three phosphorylation sites, located at Ser 394, Ser 543, and Ser 583, are reported and indicated by the symbol P. Two leucine zipper-like motifs (LZLMs) are indicated. Five GTPase motifs (GI-G5) are present in the protein. Two nuclear localization signals (NLSI and NLS2) and an accessory NLS (NLSa) are reported. The protein possesses two Menin-binding motifs: a high-affinity MBMI and a low-affinity MBM2. 
NPM1-mutated AML represents the largest group of HOX-expressing AML. A recent study provided evidence that pharmacologic inhibition of menin and DOT1L inhibited HOX and FLT3 expression and promoted differentiation of NPM1-mutated AML. ${ }^{167}$ Menin is involved also in the genesis of other tumors in addition to leukemias. Therefore, mutations of the menin gene are responsible for the development of a peculiar syndrome called multiple endocrine neoplasia type 1 syndrome, an autosomal-dominant disorder in which variable combinations of endocrine and nonendocrine tumors may occur, in the context of varied phenotypic and clinical features. ${ }^{168}$ The large majority of menin gene mutations observed in these patients are inactivating and private mutations, without any preferential distribution among selected regions of the menin gene. ${ }^{168}$

Enhanced expression of the menin-MLL complex plays an important tumorigenic role in other neoplasia such as Ewing's sarcoma ${ }^{169}$ and prostate cancer. ${ }^{170}$ In Ewing's sarcoma, expression of both menin and MLL is increased and determines enhanced HOXD expression: inhibition of MLL-menin interaction in these tumor cells decreases their tumorigenicity and inhibits HOXD expression. ${ }^{167}$ In prostate cancer cells, the overexpressed MLL-menin complex acts as a coactivator of androgenreceptor signaling and contributes to tumorigenicity. Importantly a menin inhibitor blocks androgen-receptor signaling and reduces growth of castration-resistant tumors in vivo. ${ }^{170}$

\section{Role of MLL and menin in hematopoiesis}

The study of specific knockout mice has contributed to elucidation of the role of MLL and menin 1 in normal hematopoiesis. A basic observation derived from these studies was that while normal hematopoiesis was markedly impaired in the absence of MLL, less pronounced and superimposable defects were observed in menin-deficient mice. During embryonic life, MLL expression is strictly required for the development of both primitive and definitive hematopoiesis. ${ }^{171-173}$ Furthermore, MLL is required also for adult hematopoiesis, particularly for HSC self-renewal and HPC proliferation. ${ }^{174,175}$

Menin 1 knockout results in mouse lethality during midgestation for multiple developmental defects. The possible consequence of a loss of menin 1 expression for hematopoiesis was investigated using a conditional knockout strategy. These studies showed no overt defects of hematopoiesis in menin 1-deficient mice: these mice displayed only a modest decrease in white blood-cell counts, associated with decreased clonogenic capacity of HPCs in standard methylcellulose assays ${ }^{176}$ and reduced repopulating capacity of HSCs in competitive transplantation assays. ${ }^{177}$

The analysis of regulation of hematopoiesis in mice deficient in the interaction between MLL1 and menin 1 came to the conclusion that MLL1 and its cofactor menin 1 act independently in regulating hematopoiesis at the level of HSCs. ${ }^{178}$ Both MLL1 and menin 1 play an important role in the control of B-lymphocytic cell differentiation and act largely through independent mechanisms (interestingly, some genes, such as HOXA9 and MEISI, are regulated by both proteins, but other sets of genes are specifically regulated by either MLL1 or menin 1). ${ }^{178}$ These findings support the view that these proteins are largely independent for their effects on the control of normal hematopoiesis and the disruption of menin 1-MLL interactions may represent a safe strategy to try to target selectively the aberrant gene expression deriving from the interaction between MLL-fusion proteins and menin $1 .{ }^{178}$

Developmentally induced MLL1 loss showed that deficient mice exhibit phenotypically normal fetal hematopoiesis, but rarely survive past 3 weeks of age. Surviving animals were anemic, thrombocytopenic, and exhibited a reduction in HSC number. ${ }^{179}$ The role of histone methyltransferase activity in $\mathrm{MLL1}^{-/-}$phenotypes was investigated using the MLL1 gene deleted from the SET domain, corresponding to the catalytic site, and provided evidence that histone methyltransferase activity is dispensable for the effects of MLL on hematopoiesis. ${ }^{180}$

The role of MLL1 in HSC biology was better delineated in additional studies. Artinger et al identified the transcriptional network of MLL in the hematopoietic system and showed that it extends beyond HOX genes and involves also a number of other transcriptional regulators, such as MECOM, Prdm16, Pbx1, Eya1, and others involved in HSC maintenance and proliferation. ${ }^{181}$ Furthermore, the MLLtranscription-dependent network contains genes that are both dependent and independent of menin. ${ }^{172}$ The maintenance of MLL activity on gene transcription and HSC function requires the capacity of this protein to recruit an $\mathrm{H} 4 \mathrm{k} 16$ acetyltransferase; in fact, H4k16 deacetylase inhibitors are sufficient to restore MLL1-dependent gene expression in MLL1 $^{-/-}$cells. ${ }^{181}$

\section{Menin I inhibitors}

The study and understanding of the molecular basis of MLL1-menin 1 interactions have been of fundamental importance in the development of specific small molecule 
inhibitors. The interaction between these two proteins is dictated by the binding of MLL to a large hydrophobic cavity present in the menin 1 molecule through two binding motifs: a high-affinity motif encompassing MLL residues 6-13 (MBM1), and a low-affinity motif encompassing MLL residues 24-40 (MBM2) (Figure 3). ${ }^{182}$ The MBM1 pocket is of fundamental importance for the interaction between MLL and menin 1, and represents a major site for targeting by small-molecule inhibitors. The mutation of F9 to alanine in MBM1 has a very marked impact on MLL-menin interaction. ${ }^{182}$ The role of MBM2 in MLL-menin interaction is less defined. The MBM2 motif carries a positive charge due to the presence of four arginine residues, and is seemingly involved in the mediation of electrostatic interaction with the central cavity of menin 1 , which is negatively charged. ${ }^{183}$

In line with these observations, inhibitors able to target MBM1 are capable of blocking MLL-menin interaction and suitable for preclinical and clinical studies. The first small-molecule inhibitors of the MLL-menin interaction were identified used a technology based on fluorescence polarization-based high-throughput screening. ${ }^{177}$ Among the various inhibitors identified using this approach, the most potent was the MI2 inhibitor, with an $\mathrm{IC}_{50}$ of $446 \mathrm{nM}$, able to block the interaction between MLL and menin and to inhibit the leukemogenic potential of MLL-fusion proteins. ${ }^{184}$

Analysis of the crystal structure of human menin complexed with MI2 allowed the design and the production of a more powerful inhibitor, Mi2-2, with a clear improvement in $\mathrm{IC}_{50}$ of about tenfold. ${ }^{179}$ The introduction of a cyanoindole ring connected to a thienopyrimidine core allowed the definition of a new chemical core structure suitable for the development of new specific and more potent menin inhibitors. ${ }^{185}$ This strategy led to the synthesis and characterization of two new menin inhibitors: MI463, with an $\mathrm{IC}_{50}$ of about $15 \mathrm{nM}$, and MI503, with an $\mathrm{IC}_{50}$ of about $15 \mathrm{nM} .{ }^{179}$ Both these compounds exhibit a suitable pharmacological profile based on standard preclinical studies. ${ }^{177}$ He et al identified another class of hydroxy- and aminomethyl piperidine compounds capable of mimicking the three hydrophobic interactions between MLL and menin: the most notable of these compounds, MIV6, displayed an $\mathrm{IC}_{50}$ of about $56 \mathrm{nM} .^{186}$

Other studies were based on completely different approaches. Zhou et al designed some macrocyclic peptidomimetic inhibitors, such as MCP1, able to bind the menin pocket as like the native MBM1 MLL motif: two of these compounds exhibited high $\mathrm{IC}_{50}$ in the 5-20 nM range but their high molecular weight hampered their further preclinical development. ${ }^{187}$ Finally, the screening of existing drugs allowed the identification of two drugs, the aminoglycosidic antibiotic neomycin and tobramycin, two low-affinity inhibitors with $\mathrm{IC}_{50}$ in the $20-60 \mu \mathrm{M}$ range. ${ }^{188}$

More recently, $\mathrm{Xu}$ et al, using pharmacophore-based and structure-based approaches, developed a new screening strategy to discover new inhibitors targeting the MLL-menin interface. M123, one of these compounds, displayed potent inhibitor activity with an $\mathrm{IC}_{50}$ of about $5 \mathrm{nM}$ and the capacity to inhibit the growth of MLL-rearranged leukemia cells. ${ }^{189}$ Borkin et al recently reported the synthesis and structure-based optimization of a new thienopyrimidine class of compounds able to block the interaction between MLL and menin. ${ }^{190}$ This approach led to the identification of a compound (MI136) that showed marked inhibitory activity in vitro and in vivo and seems suitable for preclinical studies. This compound displays a favorable pharmacokinetic profile. ${ }^{190}$

\section{Conclusion}

Studies carried out in the last few years have provided strong and clear evidence that multiple dysregulations of epigenetic regulatory mechanisms have a central role in leukemia onset and progression. Many epigenetic modifications are suitable for pharmacological interventions. Histone methylation is a very important process in the context of epigenetic processes of control of gene expression, and the study of these processes in leukemia has led to the identification of lysine methyltransferases and demethylases as promising targets for therapeutic interventions. In this review, we have analyzed those enzymes (LSD1 and DOT1L) or molecules (menin) and their inhibitors that have already reached the stage of initial clinical development in leukemia therapy. Although the first indications with these inhibitors are promising, future studies will clarify the real impact of these inhibitors in the treatment of leukemia and other cancers.

\section{Disclosure}

The authors report no conflicts of interest in this work.

\section{References}

1. Lawrence M, Daujat S, Schneider R. Lateral thinking: how histone modifications regulate gene expression. Trends Genet. 2016;32(1):42-56.

2. Vankatesh S, Workman JL. Histone exchange, chromatin structure and the regulation of transcription. Nature Rev Mol Cell Biol. 2015;16(3): 178-189.

3. Harr JC, Gonzalez-Sandoval A, Gasser SM. Histone and histone modifications in perinuclear chromatin anchoring: from yeast to man. $E M B O$ Rep. 2016;17(2):139-155.

4. Verdin E, Ott M. 50 Years of protein acetylation: from gene regulation to epigenetics, metabolism and beyond. Nat Rev Mol Cell Biol. 2015; 16(4):258-264. 
5. Du J, Johnson LM, Jacobsen SE, Patel DJ. DNA methylation pathways and their crosstalk with histone methylation. Nat Rev Mol Cell Biol. 2015;16(9):519-532.

6. Greer EL, Shi Y. Histone methylation: a dynamic mark in health, disease and inheritance. Nat Rev Genet. 2012;13(5):343-357.

7. Russler-Germain DA, Spencer DH, Young MA, et al. The R882H DNMT3A mutation associated with AML dominantly inhibits wild-type DNMT3A by blocking its ability to form active tetramers. Cancer Cell. 2014;25(4):442-454.

8. Spencer DH, Russler-Germain DA, Ketkar S, et al. CpG island hypermethylation mediated by DNMT3A is a consequence of AML progression. Cell. 2017;168(5):801-816.

9. Day YJ, Wang YY, Huang JY, et al. Conditional knockin of DNMT3A $\mathrm{R} 878 \mathrm{H}$ initiates acute myeloid leukemia with mTOR pathway involvement. Proc Natl Acad Sci U S A. 2017;114(20):5237-5242.

10. Shen Y, Zhu YM, Fan X, et al. Gene mutation patterns and their prognostic impact in a cohort of 1185 patients with acute myeloid leukemia. Blood. 2011;118(20):5593-5603.

11. Lin PH, Li HY, Fan SC, et al. A targeted next-generation sequencing in the molecular risk stratification of adult acute myeloid leukemia implications for clinical practice. Cancer Med. 2017;6(2):349-360.

12. Mizuno S, Chijwa T, Okamura T, et al. Expression of DNA methyltransferases DNMT1A, 3A and 3B in normal hematopoiesis and in acute and chronic myelogenous leukemia. Blood. 2001;97(5): 1172-1179.

13. Trowbridge JJ, Sinha AU, Zhu N, Li M, Armstrong SA, Orkin SH Haploinsufficiency of Dnmt1 impairs leukemia stem cell function through derepression of bivalent chromatin domains. Genes Dev. 2012 26(2):344-349.

14. Yan F, Shen N, Pang JX, et al. A vicious loop of fatty acid-binding protein 4 and DNA methyltransferase 1 promotes acute myeloid leukemia and acts as a therapeutic target. Leukemia. Epub 2017 Oct 10.

15. Shen N, Yan F, Pang JX, et al. Inactivation of receptor tyrosine kinases reverts aberrant DNA methylation in acute myeloid leukemia. Clin Cancer Res. 2017;23(20):6254-6266.

16. Tagde A, Rajabi H, Stroopinsky D, et al. MUC1-C induces DNA methyltransferase 1 and represses tumor suppressor genes in acute myeloid leukemia. Oncotarget. 2016;7(26):38974-38987.

17. Argote JA, Dasanu CA. ASXL1 mutations in myeloid neoplasms: pathogenetic considerations, impact on clinical outcome and survival. Curr Med Res Opin. Epub 2017 Jan 24.

18. Gaidzik VI, Teleanu V, Papaemmanuil E, et al. RUNX1 mutations in acute myeloid leukemia are associated with distinct clinico-pathologic and genetic features. Leukemia. 2016;30(11):2160-2168.

19. Ohgami RS, Ma L, Merker JD, et al. Next-generation sequencing of acute myeloid leukemia identifies the significance of TP53, U2AF1, ASXL1, and TET2 mutations. Mod Pathol. 2015;28(5):706-714.

20. Lund K, Adams PD, Copland M. EZH2 in normal and malignant hematopoiesis. Leukemia. 2014;28(1):44-49.

21. Göllner S, Oellerich T, Agrawal-Singh S, et al. Loss of the histone methyltransferase EZH2 induces resistance to multiple drugs in acute myeloid leukemia. Nat Med. 2017;23(1):69-78.

22. Gao L, Sun J, Liu F, Zhang H, Ma Y. Higher expression levels of the HOXA9 gene, closely associated with MLL-PTD and EZH2 mutations, predict inferior outcome in acute myeloid leukemia. Onco Targets Ther. 2016;9:711-722.

23. Sun QY, Ding LW, Tan KT, et al. Ordering of mutations in acute myeloid leukemia with partial tandem duplication of MLL (MLL-PTD). Leukemia. 2017;31(1):1-10.

24. Cao Q, Gearhart M, Gery S, et al. BCOR regulates myeloid cell proliferation and differentiation. Leukemia. 2016;30(5):1155-1165.

25. Papaemmanuil E, Gerstung M, Bullinger L, et al. Genomic classification and prognosis in acute myeloid leukemia. N Eng J Med. 2016; 374(23):2209-2221.

26. Shirai CI, Ley JN, White BS, et al. Mutant U2AF1 expression alters hematopoiesis and pre-mRNA splicing in vivo. Cancer Cell. 2015; 27(5):631-643.
27. Kim E, Ilagan JO, Liang Y, et al. SRSF2 mutations contribute to myelodysplasia by mutant-specific effects on exon recognition. Cancer Cell. 2015;27(5):617-630.

28. Döhner H, Estey E, Grimwade D, et al. Diagnosis and management of AML in adults: 2017 ELN recommendations from an international expert panel. Blood. 2017;129(4):424-447.

29. Winters A, Bernt K. MLL-rearranged leukemias: an update on science and clinical approaches. Front Pediatr. 2017;5:4.

30. Basilico S, Göttgens B. Dysregulation of haematopoietic stem cell regulatory program in acute myeloid leukemia. $J$ Mol Med (Berl). 2017;95(7):719-727.

31. Rose D, Haferlach T, Schnittger S, Perglerová K, Kern W, Haferlach C. Subtype-specific patterns of molecular mutations in acute myeloid leukemia. Leukemia. 2017;31(1):11-17.

32. Tsai CH, Hou HA, Tang JL, et al. Genetic alterations and their clinical implications in older patients with acute myeloid leukemia. Leukemia. 2016;30(7):1485-1492.

33. Gaidzik VI, Paschka P, Späth D, et al. TET2 mutations in acute myeloid leukemia (AML): results from a comprehensive genetic and clinical analysis of the AML study group. J Clin Oncol. 2012;30(12): 1350-1357.

34. Magotra M, Sakhdari A, Lee PJ, et al. Immunohistochemical loss of 5-hydroxymethylcytosine expression in acute myeloid leukemia: relationship to somatic gene mutations affecting epigenetic pathways. Histopathology. 2016;96(6):1055-1065.

35. Ahn JS, Kim HJ, Kim YK, et al. 5-Hydroxymethylcytosine correlates with epigenetic regulatory mutations, but may not have prognostic value in predicting survival in normal karyotype acute myeloid leukemia. Oncotarget. 2017;8(5):8305-8314.

36. Sperling AS, Gibson CJ, Ebert BL. The genetics of myelodysplastic syndrome: from clonal hematopoiesis to secondary leukaemia. Nat Rev Cancer. 2017;17(1):5-19.

37. Cimmino L, Dolgalev I, Wang Y, et al. Restoration of TET2 function blocks aberrant self-renewal and leukemia progression. Cell. 2017; 170(7):1078-1095.e20.

38. Medeiros BC, Fathi AT, DiNardo CD, Pollyea DA, Chan SM, Swords R. Isocitrate dehydrogenase mutations in myeloid malignancies. Leukemia. 2017;31(2):272-281.

39. Chen C, Liu Y, Lu C, et al. Cancer-associated IDH2 mutants drive an acute myeloid leukemia that is susceptible to Bdr4 inhibition. Genes Dev. 2013;27(18):1974-1985.

40. Marcucci G, Maharry K, Wu YZ, et al. IDH1 and IDH2 gene mutations identify novel molecular subsets within de novo cytogenetically normal acute myeloid leukemia: a Cancer and Leukemia Group B study. J Clin Oncol. 2010;28(14):2348-2355.

41. Stein EM, DiNardo CD, Pollyea DA, et al. Enasidenib in mutant-IDH2 relapsed or refractory acute myeloid leukemia. Blood. 2017;130(6): $722-731$.

42. Lin PH, Li HY, Fan SC, et al. A targeted next-generation sequencing in the molecular risk stratification of adult acute myeloid leukemia: implications for clinical practice. Cancer Med. 2017;6(2):349-360.

43. Bullinger L, Döhner K, Döhner H. Genomics of acute myeloid leukemia diagnosis and pathways. J Clin Oncol. 2017;35(9):934-946.

44. Hackl H, Astanina K, Wieser R. Molecular and genetic alterations associated with therapy resistance and relapse of acute myeloid leukemia. J Hematol Oncol. 2017;10(1):51.

45. Kumimoto H, Nakajima H. Epigenetic dysregulation of hematopoietic stem cells and preleukemic state. Int J Hematol. 2017;106(1):34-44.

46. Zink F, Stacey SN, Norddahl GL, et al. Clonal hematopoiesis, with and without candidate driver mutations, is common in the elderly. Blood. 2017;130(6):742-752.

47. Figueroa ME, Lugthart S, Li Y, et al. DNA methylation signatures identify biologically distinct subtypes in acute myeloid leukemia. Cancer Cell. 2010;17(1):13-27.

48. Cancer Genome Atlas Research Network. Genomic and epigenomic landscape of adult de novo acute myeloid leukemia. $N$ Engl J Med. 2013;368(22):2059-2074 
49. Akalin A, Garrett-Bakelman FE, Kormaksson M, et al. Base-pair resolution DNA methylation sequencing reveals profoundly divergent epigenetic landscapes in acute myeloid leukemia. PLoS Genet. 2012;8(6):e1002781.

50. Schoofs T, Berdel WE, Müller-Tidow C. Origins of aberrant DNA methylation in acute myeloid leukemia. Leukemia. 2014;28(1):1-14.

51. Marcucci G, Yan P, Maharry K, et al. Epigenetics meets genetics in acute myeloid leukemia: clinical impact of a novel seven-gene score. J Clin Oncol. 2014;32(6):548-556.

52. Figueroa ME, Abdel-Wahab O, Lu C, et al. Leukemic IDH1 and IDH2 mutations result in hypermethylation phenotype, disrupt TET2 function, and impair hematopoietic differentiation. Cancer Cell. 2010; 18(6):553-567.

53. Luskin MR, Gimotty PA, Smith C, et al. A clinical measure of DNA methylation predicts outcome in de novo acute myeloid leukemia. JCI Insight. 2016;1(9):e87323.

54. Li S, Garrett-Bakelman F, Chung S, et al. Distinct evolution and dynamics of epigenetic and genetic heterogeneity in acute myeloid leukemia. Nat Med. 2012;22(7):792-799.

55. Vardiman JW, Thiele J, Arber DA, et al. The 2008 revision of the World Health Organization (WHO) classification of myeloid neoplasms and acute leukemia: rationale and important changes. Blood. 2009; 114(5):937-951.

56. Arber DA, Orazi A, Hasserjian R, et al. The 2016 revision to the World Health Organization (WHO) classification of myeloid neoplasms and acute leukemia. Blood. 2016;127(20):2391-2405.

57. Kantajian H, Roboz G, Kropf P, et al. Guadecitabine (SG-110) in treatment-naïve patients with acute myeloid leukemia: phase 2 results from a multicenter, randomized, phase 1-2 trial. Lancet Oncol. 2017; 10(18):1317-1326.

58. Kropf PL, Chung WB, Kelly AD, et al. Genetic determinants of response to guadecitabine (SG-110) in AML. Blood. 2016;128(22):1680.

59. Daver N, Kantarjian HM, Roboz GJ, et al. Long term survival and clinical complete responses of various prognostic subgroups in $103 \mathrm{relapsed} /$ refractory acute myeloid leukemia (r/r AML) patients treated with guadecitabine (SG-110) in phase 2 studies. Blood. 2016; 128(22):904.

60. Welch JS, Petti AA, Miller CA, et al. TP53 and decitabine in acute myeloid leukemia and myelodysplastic syndromes. N Engl J Med. 2116; 375(21):2023-2036.

61. Sebert M, Bally C, Peterlin P, et al. Results of a phase II study of guadecitabine (SGI-110) in higher risk MDS, CMML or low blast count AML patients refractory to or relapsing after azacitidine (AZA) treatment. Blood. 2016;128(22):347.

62. Montaban-Bravo G, Bose P, Alvarado Y, et al. Initial results of a phase 2 study of guadecitabine (SGI-110), a novel subcutaneous (SC) hypomethylating agent, for patients with previously untreated intermediate-2 or high risk myelodysplastic syndromes (MDS) or chronic myelomonocytic leukemia (CMML). Blood. 2016;128(22):346.

63. Metreger L, Wissmann M, Yin N, et al. LSD1 demethylates repressive histone marks to promote androgen receptor-dependent transcription. Nature. 2005;437(7057):436-439.

64. Højfeldt JW, Agger K, Helin K. Histone lysine demethylases as targets for anticancer therapy. Nat Rev Drug Discov. 2013;12(12):917-930.

65. Stavropoulos P, Blobel G, Hoelz A. Crystal structure and mechanism of human lysine-specific demethylase-1. Nat Struct Mol Biol. 2006; 13(7):626-632.

66. Chen Y, Yang Y, Wang F, et al. Crystal structure of human histone lysinespecific demethylase 1 (LSD1). Proc Natl Acad Sci US A. 2006;103(38): 13956-13961.

67. Forneris F, Binda C, Vanoni MA, et al. Human histone demethylase LSD1 reads the histone code. J Biol Chem. 2005;280(50):41360-41365.

68. Forneris F, Binda C, Vanoni MA, Mattevi A, Battaglioli E. Histone demethylation catalyzed by LSD1 is a flavin-dependent oxidative process. FEBS Lett. 2005;579(10):2203-2207.

69. Tong JK, Hassig CA, Schnitzler GR, Kingston RE, Schreiber SL. Chromatin deacetylation by an ATP-dependent nucleosome remodeling complex. Nature. 1998;395(6705):917-921.
70. Humphrey GW, Wang Y, Russanova VR, et al. Stable histone deacetylase complexes distinguished by the presence of SANT domain protein CoREST/kiaa0071 and Mta-L1. J Biol Chem. 2001;276(9): 6817-6824.

71. You A, Tong JK, Grozinger CM, Schreiber SL. CoREST is an integral component of the CoREST-human histone deacetylase complex. Proc Natl Acad Sci U S A. 2001;98(4):1454-1458.

72. Hakimi MA, Dong Y, Lane WS, Speicher DW, Shiekhattar R. A candidate $\mathrm{X}$-linked mental retardation gene is a component of a new family of histone deacetylase-containing complexes. J Biol Chem. 2003;278(9):7234-7239.

73. Diaz AM, Somervaille T. LSD1: biologic roles and therapeutic targeting. Epigenomics. 2016;8(8):1103-1116.

74. Zheng YC, Ma J, Wang Z, et al. A systematic review of histone lysinespecific demethylase 1 and its inhibitors. Med Res Rev. 2015;35(5): 1032-1071.

75. Zibetti C, Adamo A, Binda C, et al. Alternative splicing of the histone demethylase LSD1/KDM1 contributes to the modulation of neurite morphogenesis in the mammalian nervous system. J Neurosci. 2010; 30(7):2521-2532.

76. Sprüssel A, Schulte JH, Weber S, et al. Lysine-specific demethylase 1 restricts hematopoietic progenitor proliferation and is essential for terminal differentiation. Leukemia. 2012;26(9):2039-2051.

77. Kerenyi MA, Shao Z, Hsu YJ, et al. Histone demethylase Lsd1 represses hematopoietic stem and progenitor cell signatures during blood cell maturation. Elife. 2013;2:e00633.

78. Upadhyay G, Chowdhuzy A, Vaidyanathan B, Kim D, Saleque S. Antagonistic actions of Rcor proteins regulate LSD1 activity and cellular differentiation. Proc Natl Acad Sci U S A. 2014;111(22):8071-8076.

79. Saleque S, Kim J, Rooke HM, Orkin SH. Epigenetic regulation of hematopoietic differentiation by Gfi-1 and Gfi-1b is mediated by the cofactors CoREST and LSD1. Mol Cell. 2007;27(4):562-572.

80. Anguita E, Candel FJ, Chaparro A, Roldán-Etcheverry JJ. Transcription factor GF11B in health and disease. Front Oncol. 2017;7:54.

81. Hu X, Li X, Valverde K, et al. LSD1-mediated epigenetic modification is required for TAL-1 function and hematopoiesis. Proc Natl Acad Sci US A. 2009;106(25):10141-10146.

82. Li Y, Deng C, Hu X, et al. Dynamic interaction between TAL1 oncoprotein and LSD1 regulates TAL1 junction in hematopoiesis and leukemogenesis. Oncogene. 2012;31(48):5007-5018.

83. Xu J, Bauer DE, Kerenyi MA, et al. Corepressor-dependent silencing of fetal hemoglobin expression by BCL11A. Proc Natl Acad Sci USA. 2013;110(16):6518-6523

84. Guo Y, Fu X, Jin Y, et al. Histone demethylase LSD1-mediated repression of GATA-2 is critical for erythroid differentiation. Drug Des Devel Ther. 2015;9:3153-3162.

85. Velinder M, Singer J, Bareyan D, et al. GF11 functions in transcriptional control and cell fate determination require SNAG domain methylation to recruit LSD1. Biochem J. 2016;473(19):3355-3369.

86. Thambyrajah R, Mazan M, Patel R, et al. GF11 proteins orchestrate the emergence of haematopoietic stem cells through recruitment of LSD1. Nat Cell Biol. 2016;18(1):21-32.

87. Takeuchi M, Fuse Y, Watanabe M, et al. LSD1/KDM1A promotes hematopoietic commitment of hemangioblasts through downregulation of Etv2. Proc Natl Acad Sci U S A. 2015;112(45):13922-13927.

88. Möröy T, Vanen L, Wilkes B, Khandanpour C. From cytopenia to leukemia: the role of GFil and GFilb in blood formation. Blood. 2015; 126(4):2561-2569.

89. Hönes JM, Botezatu L, Helness A, et al. GFI1 as a novel prognostic and therapeutic factor for AML/MDS. Leukemia. 2016;30(2):1237-1245.

90. Volpe G, Walton DS, Grainger DE, et al. Prognostic significance of high GFI1 expression in AML of normal karyotype and its association with a FLT3-ITD signature. Sci Rep. 2017;7(1):11148.

91. Yao H, Goldman DC, Nechiporuk T, et al. Corepressor Rcor1 is essential for murine erythropoiesis. Blood. 2014;123(20):3175-3184.

92. Yao H, Goldman DC, Fan G, et al. The corepressor Rcor1 is essential for normal myeloerythroid lineage differentiation. Stem Cells. 2015; 33(11):3304-3314 
93. Niebel D, Kirfel J, Janzen V, Höller T, Majores M, Gütgemann I. Lysine-specific demethylase 1 (LSD1) in hematopoietic and lymphoid neoplasms. Blood. 2014;124(1):151-152.

94. Harris WJ, Huang X, Lynch JT, et al. The histone demethylase KDM1A sustains the oncogenic potential of MLL-AF9 leukemia stem cells. Cancer Cell. 2012;21(4):473-487.

95. Goardon N, Marchi E, Atzberger A, et al. Coexistence of LMPP-like and GMP-like leukemia stem cells in acute myeloid leukemia. Cancer Cell. 2011;19(1):138-152.

96. Wada T, Koyama D, Kikuchi J, Honda H, Furukawa Y. Overexpression of the shortest isoform of histone demethylase LSD1 primes hemopoietic stem cells for malignant transformation. Blood. 2015;125(24): 3731-3746.

97. Schenk T, Chen WC, Göllner S, et al. Inhibition of the LSD1 (KDM1A) demethylase reactivates the all-trans-retinoic acid differentiation pathway in acute myeloid leukemia. Nat Med. 2012;18(4):605-611.

98. Niwa H, Umehara T. Structural insight into inhibitors of flavin adenine dinucleotide-dependent lysine demethylases. Epigenetics. 2017;12(5): 340-352.

99. Lee MG, Wynder C, Schmidt DM, McCafferty DG, Shiekhattar R. Histone $\mathrm{H} 3$ lysine 4 demethylation is a target of nonselective antidepressive medication. Chem Biol. 2006;13(6):563-567.

100. Zheng YC, Yu B, Chen ZS, Liu Y, Liu HM. TCPs: privileged scaffolds for identifying potent LSD1 inhibitors for cancer therapy. Epigenomics. 2016;8(5):651-666.

101. Maes T, Tirapu I, Mascaro A, et al. Preclinical characterization of a potent and selective inhibitor of the histone demethylase KDM1A for MLL leukemia. J Clin Oncol. 2013;31(15 Suppl):e13543.

102. Somervaille T, Salamero O, Montesimos P, et al. Safety, pharmacokinetics (PK), pharmacodynamics (PD) and preliminary activity in acute leukemia of Ory-1001, a first-in-class inhibitor of lysinespecific histone demethylase 1A (LSD1/KDM1A): initial results from a first-in-human phase 1 study. Poster presented at: 58th American Society of Hematology Annual Meeting; December 3-6, 2016 , San Diego, CA.

103. Neelamegam R, Ricq EL, Malvaez M, et al. Brain-penetrant LSD1 inhibitors can block memory consolidation. ACS Chem Neurosci. 2012; 3(2):120-128.

104. Cui S, Lim KC, Shi L, et al. The LSD1 inhibitor RN-1 induces fetal hemoglobin synthesis and reduced disease pathology in sickle cell mice. Blood. 2015;126(3):386-396.

105. Jagadeeswaran R, Vazquez BA, Thiruppathi M, et al. Pharmacological inhibition of LSD1 and mTOR reduces mitochondrial retention and associated ROS levels in the red blood cell of sickle cell disease Exp Hematol. 2017;50:46-52.

106. Rivers A, Vaitkus K, Ibanez V, et al. The LSD1 inhibitor RN-1 recapitulates the fetal pattern of hemoglobin synthesis in baboons (P. anubis). Haematologica. 2016;101(6):688-697.

107. Ibanez I, Vaitkus K, Rivers A, et al. Efficacy and safety of long-term RN-1 treatment to increase HbF in baboons. Blood. 2017;129(2): 260-263.

108. McGrath J, Williamson KE, Balasubramanian S, et al. Pharmacological inhibition of the histone lysine demethylase KDM1A suppresses the growth of multiple acute myeloid leukemia subtypes. Cancer Res. 2016;76(7):1975-1988

109. Mohammad HP, Smitheman KN, Kamat CD, et al. A DNA hypomethylation signature predicts antitumor activity of LSD1 inhibitors in SCLC. Cancer Cell. 2015;28(1):57-69.

110. Lee SH, Stubbs M, Liu XM, et al. Discovery of INCB059872, a novel FAD-directed LSD1 inhibitor that is effective in preclinical models of human and murine AML. Cancer Res. 2016;76(14 Suppl):4712.

111. Ye M, Liu M, Lu Y, et al. The LSD1 inhibitor INCB059872 is synergistic with ATRA in models of non-APL acute myelogenous leukemia. Cancer Res. 2016;76(14 Suppl):4696.

112. Liu X, Stubbs M, Ye M, et al. Combination of BET inhibitor INCB054329 and LSD1 inhibitor INCB059872 is synergistic for the treatment of AML in vitro and in vivo. Cancer Res. 2016;76(14 Suppl):4702.
113. Lee SH, Stubbs M, Juvekar A, et al. Combination of epigenetic regulation via LSD1 inhibition with signal transduction inhibitors significantly enhances anti-tumor activity in models of hematologic malignancies. Cancer Res. 2017;77(13 Suppl):2032.

114. Welch D, Kahen E, Cubitt CL, Reed DR. LSD1 inhibition alone and in combination with chemotherapy in Ewing sarcoma cell lines. Cancer Res. 2017;77(13 Suppl):2034.

115. Roman VD, Ye M, Liu H, et al. The evaluation of INCB059872, an FAD-directed covalent inhibitor of LSD1, in preclinical models of Ewing sarcoma. Cancer Res. 2017;77(13 Suppl):1162.

116. Lee SH, Liu XM, Diamond M, et al. The evaluation of INCB059872, on FAD-directed inhibitor of LSD1, in preclinical models of human small cell lung cancer. Cancer Res. 2017;76(14 Suppl):4704.

117. Ishikawa Y, Gamo K, Yabuki M, et al. A novel LSD1 inhibitor T-3775440 disrupts GFI1B-containing complex leading to transdifferentiation and impaired growth of AML cells. Mol Cancer Ther. 2016;16(2):273-284.

118. Ogasawara $\mathrm{D}$, Itoh $\mathrm{Y}$, Tsumoto $\mathrm{H}$, et al. Lysine-specific demethylase 1-selective inactivators: protein targeted drug delivery mechanism. Angew Chem Int Ed Engl. 2013;52(33):8620-8624.

119. Sugino M, Kawahara M, Tatsumi G, et al. A novel LSD1 inhibitor NCD38 ameliorates MDS-related leukemia with complex karyotype by attenuating leukemia programs via activating super-enhancers. Leukemia. 2017;31(11):2303-2314.

120. Ogasawara D, Suzuki T, Mino K, et al. Synthesis and biological activity of optically active NCL-1, a lysine-specific demethylase 1 selective inhibitor. Bioorg Med Chem. 2011;19(12):3702-3708.

121. Sareddy GR, Viswanadhapalli S, Surapaneni P, Suzuki T, Brenner A, Vadlamudi RK. Novel KDm1A inhibitors induce differentiation and apoptosis of glioma stem cells via unfolded protein response pathway. Oncogene. 2017;36(17):2423-2434.

122. Mould DP, McGouagle AE, Wiseman DH, Williams EL, Jordan AM. Reversible inhibitors of LSD1 as therapeutic agents in acute myeloid leukemia: clinical significance and progress to date. Med Res Rev. 2015;35(3):586-618

123. Sorna V, Theisen ER, Stephens B, et al. High-throughput virtual screening identifies novel $\mathrm{N}^{\prime}$-(1-phenylethylidene)-benzohydrazides as potent, specific, and reversible LSD1 inhibitors. J Med Chem. 2013; 56(23):9496-9508

124. Fiskus W, Sharma S, Shah B, et al. Highly effective combination of LSD1 (KDM1A) antagonist and pan-histone deacetylase inhibitor against human AML cells. Leukemia. 2014;28(11):2155-2164.

125. Liu SA, Lu WT, Li SY, et al. Identification of JL1037 as a novel, specific, reversible lysine-specific demethylase 1 inhibitor that induce [sic] apoptosis and autophagy of AML cells. Oncotarget. 2017;8(19): 31901-31914.

126. Vianello P, Sartori L, Amigoni F, et al. Thieno [3,2-b]pyrrole-5carboxiamides as new reversible inhibition of histone lysine demethylase KDM1A/LSD1 - part 2: structure-based drug design and structure-activity relationship. J Med Chem. 2017;60(5):1693-1715.

127. Mould DP, Alli C, Bremberg U, et al. Development of (4-cyanophenyl) glycine derivatives as reversible inhibitors of lysine specific demethylase 1. J Med Chem. 2017;60(19):7984-7999.

128. Mould DP, Bremberg U, Jordan AM, et al. Development and evaluation of 4-(pyrrolidin-3-yl) benzonitrile derivatives as inhibitors of LSD1. Bioorg Med Chem Lett. 2017;27(20):4755-4759.

129. Duan YC, Ma YC, Qin WP, et al. Design and synthesis of tranylcypromine derivatives as novel LSD1/HDAC dual inhibitors for cancer treatment. Eur J Med Chem. 2017;140:392-402.

130. McLean CM, Karemaker ID, van Leeuwen F. The emerging roles of DOT1L in leukemia and normal development. Leukemia. 2014;28(11): 2131-2138.

131. Feng Q, Wang $\mathrm{H}, \mathrm{Ng} \mathrm{HH}$, et al. Methylation of H3-lysine 79 is mediated by a new family of HMTases without a SET domain. Curr Biol. 2002;12(12):1052-1058.

132. Min J, Feng Q, Li Z, Zhang Y, Xu RM. Structure of the catalytic domain of human DOT1L, a non-SET domain nucleosomal histone methyltransferase. Cell. 2003;112(5):711-723. 
133. Okada Y, Feng Q, Lin Y, et al. hDOT1L links histone methylation of leukemogenesis. Cell. 2005;121(2):167-178.

134. Nguyen AT, Taranova O, He J, Zhang Y. DOT1L, the H3K79 methyltransferase, is required for MLL-AF9-mediated leukemogenesis. Blood. 2011;117(25):6912-6922.

135. Deshpande AJ, Deshpande A, Sinha AU, et al. AF10 regulates progressive H3K79 methylation and HOX gene expression in diverse AML subtypes. Cancer Cell. 2014;26(6):896-908.

136. Chen S, Yang Z, Wilkinson AW, et al. The PZP domain of AF10 senses unmodified H3K27 to regulate DOT1L-mediated methylation of H3K79. Mol Cell. 2015;60(2):319-327.

137. Li YY, Wen H, Xi YX, et al. AF9 YEATS domain links histone acetylation to DOT1L-mediated H3K79 methylation. Cell. 2014;159(3): 558-571.

138. Chen CW, Koche RP, Sinha AU, et al. DOT1L inhibits SIRT1-mdiated epigenetic silencing to maintain leukemic gene expression in MLLrearranged leukemia. Nat Med. 2015;21(4):335-343.

139. Kuntimaddi A, Achille NJ, Thorpe J, et al. Degree of recruitment of DOT1L to MLL-AF9 defines level of H3K79 di- and tri-methylation on target genes and transformation potential. Cell Rep. 2015;11(5): 808-820.

140. Okuda H, Stanogevic B, Kanai A, et al. Cooperative gene activation by AF4 and DOT1L drive MLL-rearranged leukemia. J Clin Invest. 2017;127(5):1918-1931.

141. Ran R, Rodriguez B, Luo M, et al. DOT1L as a therapeutic target for the treatment of DNMT3A-mutant acute myeloid leukemia. Blood. 2016;128(7):971-981.

142. Feng Y, Yang Y, Ortega MM, et al. Early mammalian erythropoiesis requires the Dot1L methyltransferase. Blood. 2010;116(22): 4483-4491.

143. Nguyen AT, He J, Taranova O, Zhang Y. Essential role of DOT1L in maintaining normal adult hematopoiesis. Cell Res. 2011;21(9): $1370-1373$.

144. Jo SY, Granowicz EM, Maillard I, Thomas D, Hess JL. Requirement for Dot11 in murine postnatal hematopoiesis and leukemogenesis by MLL translocation. Blood. 2011;117(18):4759-4768.

145. Daigle SR, Olhava EJ, Therkelsen CA, et al. Selective killing of mixed lineage leukemia cells by a potent small-molecule DOT1L inhibitor. Cancer Cell. 2011;20(1):53-65.

146. Daigle SR, Olhava EJ, Therkelsen CA, et al. Potent inhibition of DOT1L as treatment for MLL-fusion leukemia. Blood. 2013;122(6): 1017-1025.

147. Yu W, Chory EJ, Wernimont AK, et al. Catalytic site remodeling of the DOT1L methyltransferase by selective inhibitors. Nat Commun. 2012;3:1288.

148. Wang Y, Li L, Zhang B, et al. Discovery of novel disruptor of silencing telomeric 1-like (DOT1L) inhibitors using a target-specific function for the (s)-adenosyl-1-methionine (SAM)-dependent methyltransferase family. J Med Chem. 2017;60(5):2026-2036.

149. Waters NJ, Daigle SR, Rehlaender BN, et al. Exploring drug delivery for the DOT1L inhibitor pinometostat (EPZ-5676): subcutaneous administration as an alternative to continuous IV infusion, in the pursuit of an epigenetic target. $J$ Control Release. 2015;220(Pt B):758-765.

150. Klaus CR, Iwanowicz D, Johnston D, et al. DOT1L inhibitor EPZ5676 displays synergistic antiproliferative activity in combination with standard of care drugs and hypomethylating agents in MLL-rearranged cells. J Pharmacol Exp Ther. 2014;350(9):646-656.

151. Waters NJ, Smith SA, Olhava EJ, et al. Metabolism and disposition of the DOT1L inhibitor, pinometostat (EPZ-5676), in rat, dog and human. Cancer Chemother Pharmacol. 2016;77(1):43-62.

152. Stein EM, Garcia-Manero G, Rizzieri DA, et al. A phase 1 study of the DOT1L inhibitor, pinometostat (EPZ-5676), in adults with relapse or refractory leukemia: safety, clinical activity, exposure and target inhibition. Blood. 2015;126(23):2547.

153. Shukla N, Wetmore C, O'Brien MM, et al. Final report of phase 1 study of the DOT1L inhibitor, pinometostat (EPZ-5676), in children with relapsed or refractory MLL-2 acute leukemia. Blood. 2016; 128(22):2780.
154. Chandrasekharappa SC, Guru SC, Manickam P, et al. Positional cloning of the gene for multiple endocrine neoplasia-type 1. Science. 1997;276(5311):404-407.

155. Guru SC, Goldsmith PK, Burns AL, et al. Menin, the product of the MEN1 gene, is a nuclear protein. Proc Natl Acad Sci US A. 1998; 95(4):1630-1634.

156. Yokoyama A, Somervaille TC, Smith KS, Rozenblatt-Rosen O, Meyerson M, Cleary ML. The menin tumor suppressor protein is an essential oncogenic cofactor for MLL-associated leukemogenesis. Cell. 2005;123(2):207-218.

157. Caslini C, Yang Z, El-Osta M, Milne TA, Slany RK, Hess JL. Interaction of MLL amino terminal sequences with menin is required for transformation. Cancer Res. 2007;67(15):7275-7283.

158. Grembecka J, Belcher AM, Hartley T, Cierpicki T. Molecular basis of the mixed lineage leukemia-menin interaction: implications for targeting mixed lineage leukemias. J Biol Chem. 2010;285(52): 40690-40698.

159. Chen YX, Yan J, Keeshan K, et al. The tumor suppressor menin regulates hematopoiesis and myeloid transformation by influencing Hox gene expression. Proc Natl Acad Sci U S A. 2006;103(4):1018-1023.

160. Hughes CM, Rozenblatt-Rosen O, Milne TA, et al. Menin associated with a trithorax family histone methyltransferase complex and with the Hoxc8 locus. Mol Cell. 2004;13(4):587-597.

161. Cierpicki T, Grembecka J. Changes and opportunities in targeting the menin-MLL interaction. Future Med Chem. 2014;6(4):447-462.

162. Murai MJ, Chruszcz M, Reddy G, Grembecka J, Cierpicki T. Crystal structure of menin binding site for mixed lineage leukemia (MLL) protein. J Biol Chem. 2011;286(36):31742-31748.

163. Grembecka J, He S, Shi A, et al. Menin-MLL inhibitors reverse oncogenic activity of MLL fusion proteins in leukemia. Nat Chem Biol. 2012;8(3):277-284.

164. He S, Malik B, Borkin D, et al. Menin-MLL inhibitors block oncogenic transformation by MLL-fusion proteins in a fusion partner-independent manner. Leukemia. 2016;30(2):508-513.

165. Dafflon C, Craig VJ, Méreau H, et al. Complementary activities of DOT1L and menin inhibitors in MLL-rearranged leukemia. Leukemia. 2017;31(6):1269-1277.

166. Spencer DH, Young MA, Lamprecht TL, et al. Epigenomic analysis of the HOX gene loci reveals mechanisms that may control canonical expression patterns in AML and normal hematopoietic cells. Leukemia. 2015;29(6):1279-1289.

167. Kühn MW, Song E, Feng ZH, et al. Targeting chromatin regulators inhibits leukemogenic gene expression in NPM1 mutant leukemia. Cancer Discov. 2016;6(10):1166-1181.

168. Falchetti A. Genetics of multiple endocrine neoplasia type 1 syndrome: what's new and what's old. F1000Res. 2017;6:73.

169. Svoboda LK, Bailey N, Van Noord RA, et al. Tumorigenicity of Ewing sarcoma is critically dependent on the trithorax proteins MLL1 and menin. Oncotarget. 2017;8(1):458-471.

170. Malik R, Khan AP, Asangani IA, et al. Targeting the MLL complex in castration-resistant prostate cancer. Nat Med. 2015;21(4):344-352.

171. Hess JL, Yu BD, Li B, Hanson R, Korsmeyer SJ. Defects in yolk sac hematopoiesis in MLL-null embryos. Blood. 1997;90(5):1799-1806.

172. Yagi H, Deguchi K, Aono A, Kishimoto T, Komori T. Growth disturbance in fetal liver hematopoiesis of MLL-mutant mice. Blood. 1998; 92(1):108-117.

173. Ernst P, Fisher JK, Avery W, Wade S, Foy D, Korsmeyer SJ. Definitive hematopoiesis requires the mixed-lineage leukemia gene. Dev Cell. 2004;6(3):437-443.

174. Jude CD, Climer L, Xu D, Artinger E, Fisher JK, Ernst P. Unique and independent roles for MLL in adult hematopoietic stem cells and progenitors. Cell Stem Cell. 2007;1(3):324-337.

175. McMahon KA, Hiew SY, Hadjur S, et al. MLL has a critical role in fetal and adult hematopoietic stem cell self-renewal. Cell Stem Cell. 2007;1(3):338-345.

176. Maillard I, Chen YX, Friedman A, et al. Menin regulates the function of hematopoietic stem cells and lymphoid progenitors. Blood. 2009; 113(8):1661-1669. 
177. Maillard I, Hess JL. The role of menin in hematopoiesis. Adv Exp Med Biol. 2009;668:51-57.

178. Li B, Gan T, Meyerson M, Rabbitts TH, Ernst P. Distinct pathways regulated by menin and by MLL1 in hematopoietic stem cells and developing B cells. Blood. 2013;122(12):2039-2046.

179. Gant T, Jude CD, Zaffuto K, Ernst P. Developmentally induced MLL1 loss reveals defects in postnatal haematopoiesis. Leukemia. 2010;24(10):1732-1741.

180. Mishra BP, Zaffuto KM, Artinger EL, et al. The histone methyltransferase activity of MLL1 is dispensable for hematopoiesis and leukemogenesis. Cell Rep. 2014;7(4):1239-1247.

181. Artinger EL, Mishra BP, Zaffuto KM, et al. An MLL-dependent network sustains hematopoiesis. Proc Natl Acad Sci U S A. 2013; 110(29):12000-12005.

182. Grembecka J, Belcher AM, Hartley T, Cierpicki T. Molecular basis of the mixed lineage leukemia-menin interaction: implication for targeting mixed lineage leukemias. J Biol Chem. 2010;285(52):40690-40698.

183. Dhi A, Murai MJ, He S, et al. Structural insights into inhibition of the bivalent menin-MLL interaction by small molecules in leukemia. Blood. 2012;120(23):4461-4469.

184. Grembecka J, He S, Shi A, et al. Menin-MLL inhibitors reverse oncogenic activity of MLL fusion proteins in leukemia. Nat Chem Biol. 2012;8(3):277-284.

185. Borkin D, He S, Miao H, et al. Pharmacologic inhibition of the meninMLL interaction blocks progression of MLL leukemia in vivo. Cancer Cell. 2015;27(4):589-602.

186. He S, Senter TJ, Pollock J, et al. High-affinity small-molecule inhibitors of the menin-mixed lineage leukemia (MLL) interaction closely mimic a natural protein-protein interaction. J Med Chem. 2014;57(4): $1543-1556$.
187. Zhou H, Liu L, Huang J, et al. Structure-based design of high-affinity macrocyclic peptidomimetics to block the menin-mixed lineage leukemia 1 (MLL 1) protein-protein interaction. J Med Chem. 2013; 56(3):1113-1123.

188. Li L, Zhou R, Geng H, et al. Discovery of two aminoglycoside antibiotics as inhibitors targeting the menin-mixed lineage leukemia interface. Bioorg Med Chem Lett. 2014;24(9):2090-2093.

189. Xu Y, Yue L, Wang Y, et al. Discovery of novel inhibitors targeting the menin-mixed lineage leukemia interface using pharmacophoreand docking-based virtual screening. J Chem Inf Model. 2016;56(9): $1847-1855$.

190. Borkin D, Pollock J, Kempinska K, et al. Property focused structurebased optimization of small molecule inhibitors of the protein-protein interaction between menin and mixed lineage leukemia. J Med Chem. 2016;59(3):892-913.

191. Spurr SS, Bayle ED, Yu W, et al. New small molecule inhibitors of histone methyl transferase DOT1L with a nitrile as a non-traditional replacement for heavy halogen atoms. Bioorg Med Chem Lett. 2016; 26(18):4518-4522.

192. Chen C, Zhu H, Stauffer F, et al. Discovery of novel Dot1L inhibitors through a structure-based fragmentation approach. ACS Med Chem Lett. 2016;7(8):735-740.

193. Möbitz H, Machauer R, Holzer P, et al. Discovery of potent, selective, and structurally novel Dot $1 \mathrm{~L}$ inhibitors by a fragment linking approach. ACS Med Chem Lett. 2017;8(3):338-343.
OncoTargets and Therapy

\section{Publish your work in this journal}

OncoTargets and Therapy is an international, peer-reviewed, open access journal focusing on the pathological basis of all cancers, potential targets for therapy and treatment protocols employed to improve the management of cancer patients. The journal also focuses on the impact of management programs and new therapeutic agents and protocols on

\section{Dovepress}

patient perspectives such as quality of life, adherence and satisfaction. The manuscript management system is completely online and includes a very quick and fair peer-review system, which is all easy to use. Visit http://www.dovepress.com/testimonials.php to read real quotes from published authors. 